\title{
Taking Financial Frictions to the Data*
}

\author{
Hyunduk Suh ${ }^{\dagger} \quad$ Todd B. Walker
}

August 2015

\begin{abstract}
We estimate a Dynamic Stochastic General Equilibrium (DSGE) model with various financial frictions and analyze how well the model explains the Great Recession. Predictive analysis shows that the model can only slightly better explain the large deviation from trend during the crisis relative to a model without financial frictions. Specifically, the risk premium shock, which is a shock to the external finance premium of the entrepreneurs' leverage, explains the largest part of the investment downfall during the crisis. However, the 'balance sheet' channel of financial frictions in the model, which structurally links balance sheet conditions of financial intermediaries and nonfinancial borrowers to their borrowing rates, is estimated to be weak. We examine alternative prior specifications for how the financial frictions enter the model and continue to find a limited role for these frictions. Rolling-window estimation provides evidence for substantial time variation in parameters governing financial frictions. We conclude that the well-known financial frictions studied in this paper are not able to explain the financial crisis in a linearized and estimated model.
\end{abstract}

Keywords: Bayesian estimation, DSGE model, financial friction.

JEL Codes: E44, E52, E59

\footnotetext{
${ }^{*}$ We thank Eric Leeper, Thomas Lubik, an associate editor, and two anonymous referees for helpful comments. Walker acknowledges support from NSF Grant SES 096221.

${ }^{\dagger}$ Inha University; hsuh@inha.ac.kr

‡Indiana University; walkertb@indiana.edu
} 


\section{Introduction}

We analyze the 2007-2009 US financial crisis episode using a medium-scale Dynamic Stochastic General Equilibrium (DSGE) model with various financial frictions. Prior to the crisis, the benchmark model estimated and used for policy analysis was a version of Christiano et al. (2005) and Smets and Wouters (2007), which was equipped with various real and nominal frictions but generally lacked financial frictions. ${ }^{1}$ This led to an underestimation of the consequences that financial risk poses, potentially undermining the model's predictive power during the crisis period.

In response to the crisis, several papers have introduced a micro-founded financial sector into the standard model. The purpose of this paper is to assess the efficacy of a subset of these models. In particular, we are interested in the extent to which a linearized model with well-known financial frictions, estimated using Bayesian methods, is able to predict and explain the extreme events of the 2007-2009 financial crisis. We conduct the following thought experiment. First, we incorporate various financial frictions into the standard New Keynesian DSGE model of Smets and Wouters (2007) (SW model hereafter). In particular, we introduce financial frictions between non-financial entrepreneurs and financial intermediaries, between credit-constrained households and financial intermediaries, and within financial intermediaries. As we discuss below, these frictions are well established in the literature. We then estimate the structural parameters of the model (SW-FF model hereafter) using Bayesian methods. Conditional on the estimated parameters, we assess the overall performance of the SW-FF model relative to the standard SW model. Specifically, we conduct prior-posterior predictive analysis to examine whether the model with financial frictions is better suited for explaining the large volatility and comovement of macro aggregates over the crisis period. We then use historical decompositions to examine how each financial friction and external shock contributes to the joint dynamics of aggregates (Section 4.2). We decompose forecast error variances to see the influence of financial shocks on financial indicator variables and non-financial variables in the estimated model (Section 4.4). Lastly we examine time variation in parameter values by estimating the model using a rolling window of data (Section 4.5).

Prior-predictive analysis shows that the SW-FF model is better suited, relative to the SW model, to explain the dynamics of the crisis (Section 4.1). Prior to taking the model to data, the model with financial frictions is more versatile in the sense that it allows for a much larger range of aggregate dynamics. For example, a substantial decline in investment, similar to the last two quarters of 2008, is an extremely rare event in the SW model, but not as unlikely when financial frictions are added.

However, posterior analysis imposes a limited role for the financial friction channels. The 'balance sheet' channel of financial frictions, the link between the balance sheet of financial intermediaries and nonfinancial borrowers and their borrowing rates, is inconsequential. Although there are large negative shocks to the balance sheets of entrepreneurs and financial intermediaries, the estimated effects on consumption and investment are limited. Financial shocks account for

\footnotetext{
${ }^{1}$ The model did include a "financial wedge" but lacked a micro-founded financial sector. See Faust and Gupta (2012) for an assessment of this model's performance over the crisis period.
} 
the lion's share of variance decompositions of financial indicator variables, but only a small part of non-financial variables. Historical decompositions demonstrate that the risk premium shock, which is the shock to the external finance premium given the entrepreneurs' leverage, explains the largest part of the investment downfall. However, it does not explain the simultaneous downfall in consumption, as the model still has to rely mostly on non-financial shocks to explain consumption dynamics.

Our results suggest that the linearized / estimated NK model, even with well-established financial frictions, is incapable of fully endogenizing the interactive dynamics between the financial and non-financial (real) sectors of the economy.

There are several potential reasons why the financial frictions modeled here do not play a more prominent role. First, it could be that the way in which financial frictions are incorporated into the model that is minimizing their impact. Indeed several papers have emphasized that the financial crisis was not due to firms' balance sheets nor could it be attributed to traditional credit channels-as we model here-but to runs on various banks' liabilities [Gorton and Metrick (2009), Morris and Shin (2008), Brunnermeier and Sannikov (2014)]. Our model does not incorporate bank runs. Angeloni and Faia (2013) build a macro model that includes fundamental banks runs as a propagation mechanism and risk taking. ${ }^{2}$ Second, our linearized model does not account for default or endogenous risk. The collateral constraint imposed in our setup is designed to all but eliminate household default, which substantially mitigates the propagation of financial shocks. A mechanism similar to Kovrijnykh and Livshits (2013), which generates equilibrium defaults on mortgages, would improve the model along this dimension. Finally, the combination of Gaussian shocks and linearization could be insufficient for capturing the collapse in macro aggregates over the 2007-2009 period. While a thorough analysis of nonlinearities and non-Gaussian behavior is beyond the scope of the current paper, we conduct a rolling-window estimation to get a sense for how much time variation exists in parameters governing financial frictions. We find substantial time variation but the model continues to fall short of being able to explain the great recession.

\section{MOdEL}

In this section, we propose a model that builds upon the SW setting by adding well-known financial frictions to the household's problem, the business sector and by introducing financial intermediaries.

2.1 "Standard" Financial Frictions As discussed in the Introduction, our model lacks two important elements of the financial crisis-a run on banks' liabilities and endogenous default. However, the financial frictions adopted in this paper are fairly standard in the literature. A financial accelerator mechanism, introduced by Bernanke et al. (1999), applies to the contract between entrepreneurs and the financial intermediaries. This mechanism highlights the relationship between borrower leverage and required external finance premium, and explains how the relationship plays a

\footnotetext{
${ }^{2}$ Angeloni et al. (2014) and Angeloni et al. (2015) show that this type of financial friction is better equipped to explain the large recession following the financial crisis.
} 
role in the propagation and persistence of shocks, especially regarding business investment dynamics. The usefulness of this mechanism in business cycle analysis has been supported by numerous empirical works, such as Christensen and Dib (2008), De Graeve (2008), and von Heideken (2009). Another friction used in this paper is a borrowing constraint in the type of Kiyotaki and Moore (1997) which applies to the contract between credit-constrained households and the financial intermediaries. This constraint is imposed because moral hazard problems prevent borrowers from financing beyond the liquidation value of the collateral. In this paper, a collateral constraint is imposed as in Iacoviello (2005), and Iacoviello and Neri (2010). Households are credit-constrained because they are impatient, and they use their housing goods as collateral, allowing housing market conditions to impact the business cycle. Finally, we allow the balance sheets of financial intermediaries to affect their ability to draw loanable funds and therefore to intermediate credit. In particular, we use the 'distance-to-default' measure of Merton (1974) applied to the financial sector following Carlson et al. (2011) as a proxy for balance sheet strength. Also, we allow that the distance-todefault to interact with the spread between the required return for the intermediary asset and the risk-free rate.

The role of the balance sheets of financial intermediaries in perpetuating business cycle fluctuations in a DSGE setting has been given a lot of attention recently. Meh and Moran (2010) introduces a moral hazard problem with respect to the monitoring function of banks by Holmstrom and Tirole (1997), to explain the role of bank capital in credit intermediation. Gertler and Karadi (2011), Gertler and Kiyotaki (2010) suggests an endogenous requirement for bank capital, arising from moral hazard problems in which banks can divert some of its funds. ${ }^{3}$ Angeloni and Faia (2013) introduces a fragile banking sector via Diamond and Rajan (2000) into a DSGE model with nominal rigidities, where the bank faces a possible bank run and chooses optimal level of bank capital. However, these papers have not been rigorously been taken to the data.

The model in this paper is the closest to Lombardo and McAdam (2012), which studies the role of financial frictions in the Euro zone using a New Keynesian model that incorporates a financial accelerator into the business sector and a collateral constraint on the household. It shows that financial shocks are not the most dominant factor for GDP downfall during the financial crisis. There are also other attempts to use the financial friction DSGE model to interpret the recent financial crisis. Brzoza-Brzezina and Kolasa (2013) compares the financial accelerator model and the collateral constraint model, and mentions that 2007-2009 financial crisis is not identified by those models as the event particularly caused by financial frictions. On the other hand, Merola (2013) augments Smets and Wouters (2007) with financial accelerator model and concludes that financial shocks explain a large part of the recent financial crisis. This paper is distinguished by the following standpoint in the literature. First, this paper presents richer description about the financial sector, with a financial intermediary balance sheet friction interacting with macroeconomic

\footnotetext{
${ }^{3}$ Another possible misspecification of our model could be that this friction implies that banks' balance sheets are pro-cyclical and that spreads behave counter-cyclically. However this is at odds with the empirical financial literature, which provides an explanation as to why those types of banks' balance sheet frictions do not appear empirically relevant.
} 
variables. Second, this paper provides more detailed analysis of the role of financial frictions on various macro variables during 2007-2009 financial crisis. Third, this paper distinguishes clearly the propagation mechanisms. Finally, prior-posterior predictive analysis enables us to assess the model's usefulness predicting extreme events such as financial crises.

2.2 Financial Crisis Interpreted by SW Model Prior to incorporating financial frictions, we first document how the financial crisis is interpreted by the standard SW model [Smets and Wouters (2007)]. Figure 1 shows the historical decomposition of quarterly US output change (deviation from trend) for the standard SW model [Smets and Wouters (2007)]. This decomposition shows the contribution of each structural shock to the changes in output. Suppose our original structural model is $A X_{t}=B X_{t-1}+\varepsilon_{t}$ and its reduced form vector autoregressive (VAR) representation is $X_{t}=A^{-1} B X_{t}+A^{-1} \varepsilon_{t} \equiv C X_{t-1}+e_{t}$. This VAR has an moving-average (MA) representation of the form

$$
X_{t}=C^{t} X_{0}+\sum_{i=0}^{t-1} C^{i} e_{t-i}=C^{t} X_{0}+\sum_{i=0}^{t-1} \Psi_{t-i} \varepsilon_{t-i} .
$$

Given the estimates of model parameters and structural shocks, we can calculate the contribution of $j$ th structural shock $\varepsilon_{j}=\left(\epsilon_{j, 1}, \epsilon_{j, 2}, \ldots, \epsilon_{j, t}\right)^{\prime}$ to $k$ th variable $X_{k}=\left(X_{k, 1}, X_{k, 2}, \ldots, X_{k, t}\right)^{\prime}$, by assuming (counterfactually) $\varepsilon_{\forall l \neq j}=0$ in the above MA representation. To obtain the historical decomposition from SW model, posteriors are estimated with US data from 1974:4 to 2011:4, and evaluated at the mode. ${ }^{4}$

Figure 1 shows that a large fraction of the crisis in the 4th quarter of 2008 is attributable to the financial friction shock ${ }^{5}$, as it accounts for roughly $80 \%$ of the decrease in output. This shock is a wedge between the interest rate controlled by the central bank and the return on assets held by the households. A positive realization of this shock can be interpreted as 'flight to quality' as it increases the interest rate spread and decreases consumption and investment. Although this is a convenient way of capturing frictions in the financial sector, a more structural exploration is warranted. In the next section, we discuss ways to enrich this macro-finance relationship.

2.3 Financial Friction in the Business Sector We introduce a financial friction in the business sector via the accelerator mechanism of Bernanke et al. (1999). More specifically, there are two additional economic agents involved in the capital investment process, entrepreneurs and capital-goods producers. Entrepreneurs effectively choose the capital stock each period. Capital investment is financed by external borrowing and net worth. Net worth of the entrepreneurs is defined as the retained earnings from the previous period.

\footnotetext{
${ }^{4}$ The prior and posterior estimation results of the original SW model are presented in the appendix.

${ }^{5}$ Smets and Wouters (2007)'s original name for this shock is 'risk premium shock'. However, we call it as 'financial friction shock' to distinguish it from the risk premium shock we later define.
} 


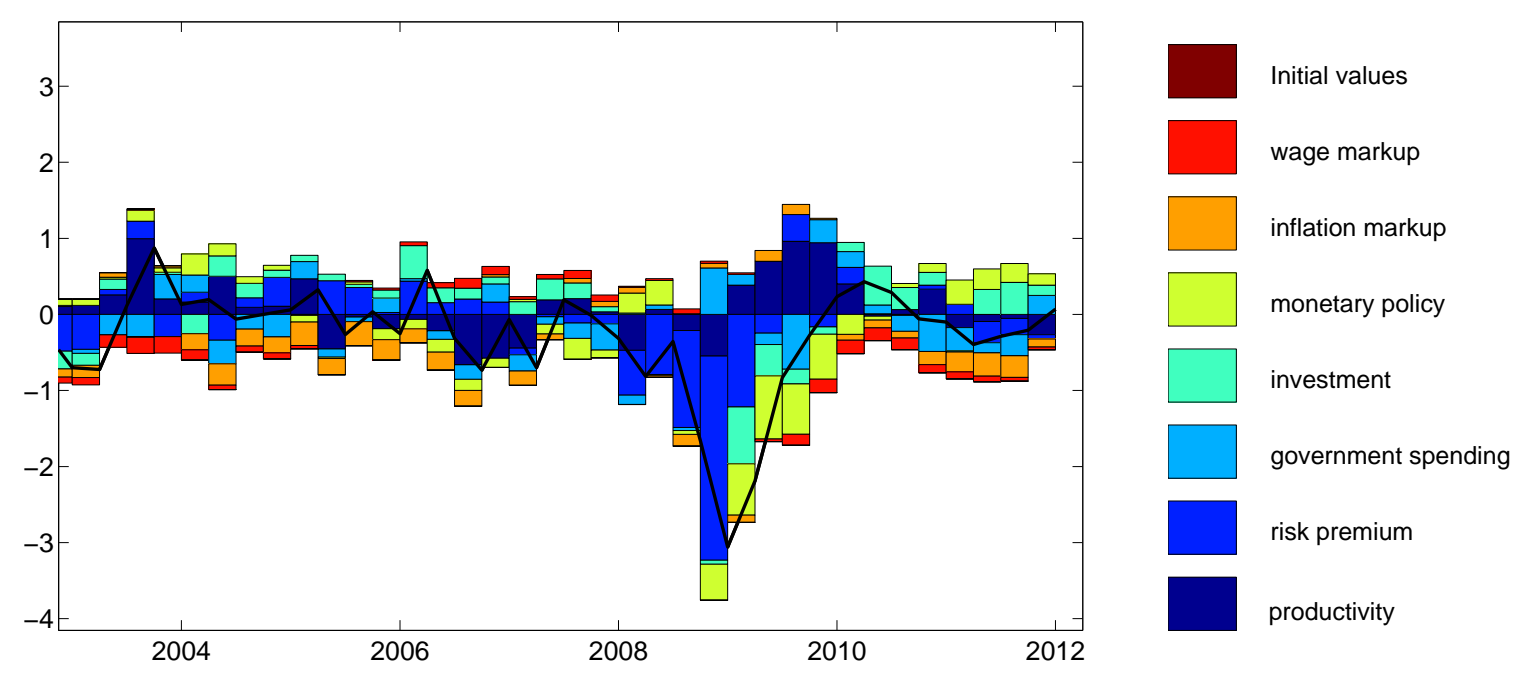

Figure 1: Historical decomposition, changes in output, deviation from trend (\%)

The key equation that characterizes the financial accelerator mechanism is given by

$$
E_{t}\left(\frac{R_{t+1}^{K}}{R_{t}^{b}}\right)=f\left(\frac{Q_{t} K_{t}^{p}}{N W_{t}}\right) \varepsilon_{t}^{r p}
$$

where $K_{t}^{p}$ is the physical capital stock, $Q_{t}$ is the price of capital, $N W_{t}$ is the net worth of the entrepreneur, $\varepsilon_{t}^{r p}$ is a shock to the risk premium and $f$ is assumed to be an increasing function. $R_{t}^{K}$ is the return on capital, and $R_{t}^{b}$ is the intermediary's funding cost that will be explained in section 3.4. The above equation shows that the external finance premium, defined by $E_{t}\left(R_{t+1}^{K} / R_{t}^{b}\right)$, will be an increasing function of the ratio of total assets over net worth $\left(Q_{t} K_{t}^{p} / N W_{t}\right)$, where the size of business loan is defined by

$$
B_{t}^{e}=Q_{t} K_{t}^{p}-N W_{t}
$$

The return on capital is determined by the marginal productivity of capital and the price change of capital,

$$
R_{t}^{k}=\frac{M P_{k}+(1-\delta) Q_{t}}{Q_{t-1}}
$$

The entrepreneurs' net worth is defined by net returns after repaying the debt obligation. The law of motion for the net worth is thus given by

$$
N W_{t}=\vartheta\left[R_{t}^{k} Q_{t-1} K_{t-1}^{p}-R_{t-1}^{b}\left(Q_{t-1} K_{t-1}^{p}-N W_{t-1}\right)\right] \varepsilon_{t}^{n w}
$$

where $\vartheta$ is the survival rate of the entrepreneurs for each period. Equation (4) shows that the net 
worth of the surviving entrepreneurs is the retained earnings from the investment after subtracting off the portion claimed by the intermediary. $\varepsilon_{t}^{n w}$ is a shock to the entrepreneurs' net worth, which represents the unexpected gain or loss that affects the entrepreneur's balance sheet.

Given the size of physical capital stock, entrepreneurs also determine the utilization rate. It is assumed that capital utilization has costs determined by $a\left(u_{t}\right)$, and the entrepreneurs' decision regarding capital utilization is made by solving the following optimization problem,

$$
\max _{u} M P_{k} \cdot K_{t}-a\left(u_{t}\right) K_{t-1}^{p}, \quad K_{t}=K_{t-1}^{p} \cdot u_{t} .
$$

Capital goods producers purchase $I_{t}$ amounts of consumption goods at a price of one, and turn them into the same amount of new capital. Transformation costs, $s(\cdot)$, arise during the process, and the capital is resold to entrepreneurs at price $Q_{t}$. Capital goods producers maximize future discounted expected return, given by the following optimization problem

$$
\max _{I} \sum_{s=0}^{\infty} \bar{\beta}^{s} \varepsilon_{t+s}^{\beta} E_{t}\left[Q_{t+s}-\left\{1+s\left\{I_{t+s} / I_{t+s-1}\right\} \varepsilon_{t+s}^{i}\right] I_{t+s}\right.
$$

where $\varepsilon_{t}^{i}$ is the investment specific shock that affects the efficiency of capital accumulation process.

\subsection{Credit-constrained Households There exist housing goods and credit constrained bor-} rowing households, as in Iacoviello and Neri (2010). Households are distinguished by patient households and impatient households. Impatient households have lower future discount parameter than patient households $\left(\beta^{\prime}<\beta\right)$. There are a continuum of agents in each household group. The economic size of each group is determined by its share of wage income, which is characterized by the parameter $\mu$. Impatient households are borrowers in the steady state and around its neighborhood. Households have preferences over not only consumption goods but also housing goods.

Patient households maximize

$$
E_{t} \sum_{s=0}^{\infty} \beta^{s} \varepsilon_{t+s}^{\beta}\left[\frac{1}{1-\sigma_{c}} J_{t+s}^{1-\sigma_{c}}\right] \exp \left[\frac{\sigma_{c}-1}{1+\sigma_{l}} L_{t+s}^{1+\sigma_{l}}\right]
$$

where $J$ is a composite of consumption and housing goods

$$
J_{t}=\left[(1-\psi)\left(C_{t}-\lambda C_{t-1}\right)^{1-\sigma_{h}}+\psi \varepsilon_{t}^{\psi}\left(H_{t}\right)^{1-\sigma_{h}}\right]^{\frac{1}{1-\sigma_{h}}},
$$

subject to the budget constraint

$$
\begin{aligned}
& C_{t+s}+\frac{D_{t+s}}{R_{t+s} P_{t+s}}+\frac{S_{t+s}}{R_{t+s} P_{t+s}}+T_{t+s}+\frac{Q_{t+s}^{h}}{P_{t+s}} H_{t+s} \\
\leq & \frac{D_{t+s}}{P_{t+s}}+\frac{S_{t+s}}{P_{t+s}}+\frac{W_{t+s}^{h} L_{t+s}}{P_{t+s}}+\frac{Q_{t+s}^{h}}{P_{t+s}}\left(1-\delta_{h}\right) H_{t+s-1}+D i v_{t+s} .
\end{aligned}
$$


In the utility function, $C$ is consumption, $H$ is housing goods and $L$ is the labor supply. In the budget constraint, $D$ is the nominal deposit, $S$ is the nominal bank equity, $R_{t}$ is the nominal gross saving interest rate, $P$ is the price of consumption goods, $T$ is lump-sum tax, $Q^{h}$ is nominal housing price and $\delta_{h}$ is the depreciation rate of housing goods. $W^{h}$ is the wage received and Div is the dividend income from firms. $\varepsilon_{t}^{\psi}$ is a preference shock for the housing goods that affects housing demand. $\varepsilon_{t}^{\beta}$ is a shock affecting the discount factor, which is different from financial friction shock in the standard SW model. This is because the discount factor shock only affects the intertemporal consumption decision while financial friction shock in the SW model affects both the intertemporal consumption and investment decision as it introduces a wedges between the rate at which households save and borrow.

Impatient households maximize

$$
E_{t} \sum_{s=0}^{\infty}{\beta^{\prime}}^{s} \varepsilon_{t+s}^{\beta}\left[\frac{1}{1-\sigma_{c}} J_{t+s}^{\prime}{ }^{1-\sigma_{c}}\right] \exp \left[\frac{\sigma_{c}-1}{1+\sigma_{l}} L_{t+s}^{\prime}{ }^{1+\sigma_{l}}\right]
$$

where

$$
J_{t}^{\prime}=\left[(1-\psi)\left(C_{t}^{\prime}-\lambda C_{t-1}^{\prime}\right)^{1-\sigma_{h}}+\psi \varepsilon_{t}^{\psi} H_{t}^{\prime 1-\sigma_{h}}\right]^{\frac{1}{1-\sigma_{h}}}
$$

subject to the budget constraint

$$
\begin{aligned}
& C_{t+s}^{\prime}+T_{t+s}^{\prime}+\frac{Q_{t+s}^{h}}{P_{t+s}} H_{t+s}^{\prime}+\frac{B_{t+s-1}^{\prime} R_{t+s-1}^{b}}{P_{t+s}} \\
\leq & \frac{B_{t+s}^{\prime}}{P_{t+s}}+\frac{W_{t+s}^{h \prime} L_{t+s}^{\prime}}{P_{t+s}}+\frac{Q_{t+s}^{h}}{P_{t+s}}\left(1-\delta_{h}\right) H_{t+s-1}^{\prime}+D i v_{t+s}^{\prime}
\end{aligned}
$$

and the collateral (loan-to-value) constraint

$$
\frac{B_{t}^{\prime}}{P_{t}} \leq m \varepsilon_{t}^{d b t} E_{t} q_{t+1}^{h} H_{t}^{\prime}
$$

where $B_{t}^{\prime}$ is nominal household debt. The parameter $m$ determines the steady state loan-to-value (LTV) ratio, which is the ratio of debt to collateral value, as in Kiyotaki and Moore (1997). The impatient households' ability to borrow is limited by the value of collateral asset that can be liquidated. As in Iacoviello (2005), housing goods are used as the collateral asset, and the constraint binds around the steady-state and its neighborhood. LTV ratio is assumed to vary over time, as $\varepsilon_{t}^{d b t}$ denotes an external disturbance to lending standards.

2.5 Production For the consumption goods sector, the production technology of intermediate goods producers is Cobb-Douglas, similar to that of the SW model,

$$
Y_{t}=A_{t} K_{t}^{\alpha}\left[\gamma^{t} L_{t}^{a}\right]^{1-\alpha}-\gamma^{t} \Phi
$$


Here $A$ is technology shock, $K$ is non-residential capital service which is the physical capital multiplied by the utilization rate, $\gamma$ is labor force trend factor, $\Phi$ is the fixed cost in production and $\alpha$ is the capital share of production in Cobb-Douglas technology. $L^{a}$ is the aggregate labor of patient and impatient households $\left(L_{t}^{a}=\left(L_{t}\right)^{\mu}\left(L_{t}^{\prime}\right)^{1-\mu}\right)$. The rest of the production side of the economy for intermediate goods producers and final goods producers are identical to the SW model and omitted to save space.

The resource constraint of this economy is given by

$$
Y_{t}=C_{t}+C_{t}^{\prime}+I_{t}+I K_{t}^{h}+G_{t}+a\left(u_{t}\right) K_{t}
$$

where $I K^{h}$ is the capital investment earmarked for housing.

In the literature that features housing goods in DSGE models, it is more conventional to use a Cobb-Douglas production technology for housing as in Paries and Notarpietro (2008) and Iacoviello and Neri (2010). However, here we simply assume that housing good producers have a linear technology that transforms residential investment into housing goods that accumulate over the last period's housing stock net of depreciation. The reason is that the linear technology is more consistent with the description of the residential investment item in national account statistics. ${ }^{6}$

The optimization problem of housing good producers is given by

$$
\max _{I K^{h}} E_{t}\left[Q_{t}^{h} A_{t}^{h}-\left\{1+s^{h}\left(I K_{t}^{h} / I K_{t-1}^{h}\right)\right\}\right] I K_{t}^{h},
$$

and the law of motion for aggregate housing goods is given by

$$
H_{t}^{a}-\left(1-\delta_{h}\right) H_{t-1}^{a}=I H_{t}=A_{t}^{h} I K_{t}^{h} \quad\left(H_{t}^{a}=H_{t}+H_{t}^{\prime}\right)
$$

where $s^{h}(\cdot)$ is adjustment cost for residential capital investment, and $I H_{t}$ denotes gross housing production.

2.6 Financial Intermediaries We model the financial sector by focusing on the relationship between intermediaries' balance sheet and their ability to intermediate credit. As mentioned, this type of friction has substantial empirical backing and is believed to be a key factor during the 2007 - 2009 financial crisis [Adrian and Shin (2010), Meh and Moran (2010), Gertler and Kiyotaki (2010), and Gertler and Karadi (2011)].

One of the novel aspects of our modeling approach is that we use 'distance to default' as an observable variable to capture the riskiness of the financial sector. Distance to default is an indicator of default probability originally developed by Merton (1974) who, using the methodology of Black and Scholes (1973), demonstrated how equity could be modeled as a call option on the assets of the firm with a strike price equal to the firm's liabilities. By assuming a simple capital structure, Merton was able to calculate the default probability via (now) well-known derivative

\footnotetext{
${ }^{6}$ In national account statistics, residential investment includes contractor's profits, labor cost used for the construction of housing goods as well as the cost of materials installed.
} 
pricing equations.

Specifically, assume the firm's assets are financed by equity issued at time $t$ denoted by $S_{t}$, and zero-coupon debt issued at $t\left(D_{t}\right)$ with a face value of $F$ and maturity date $M$. The market value of the firm at any date $t$ is given by the sum of the market value of debt and equity. Therefore, the accounting identity $V_{t}=S_{t}+D_{t}$, where $V_{t}$ denotes firm value, holds for each period. Under these assumptions, the bondholders are entitled to a time- $M$ cash flow of $\min \left[V_{M}, F\right]$ and since equity holders are the residual claimants, the value of equity at time $M$ is given by $\max \left[V_{M}-F, 0\right]$. At any time $t<M$, the value of these derivative securities is

$$
\begin{gathered}
S_{t}=e^{-r(M-t)} \mathbb{E}_{t}^{Q}\left\{\max \left[V_{M}-F, 0\right]\right\} \\
D_{t}=e^{-r(M-t)} \mathbb{E}_{t}^{Q}\left\{\min \left[V_{M}, F\right]\right\}
\end{gathered}
$$

where the expectation is taken with respect to the risk-neutral probability measure and the risk-free rate $r$ is assumed to be constant over time.

Assuming a geometric Brownian motion for firm value, Merton showed the probability of default for the firm can be backed out of (17) and (18), and is given by ${ }^{7}$

$$
\pi_{t}^{D}=\operatorname{Pr}\left(-\frac{\ln \left(V_{t}\right)-\ln (F)+\left(\mu_{V}-\sigma_{V}^{2} / 2\right) J}{\sigma_{V} \sqrt{M}} \geq \varepsilon_{t+M}\right) .
$$

where $\varepsilon_{t+M}$ is white noise.

We can then define the distance to default as

$$
D D_{t}=\frac{\ln \left(V_{t} / F\right)+\left(\mu_{V}-\sigma_{V}^{2} / 2\right) M}{\sigma_{V} \sqrt{M}}
$$

Default occurs when the ratio of firm value to debt $\left(V_{t} / F\right)$ drops below unity or the log of the ratio is negative. The distance to default $D D_{t}$ can be interpreted as a z-score, which gives the number of standard deviations the log of this ratio needs to deviate from its mean in order for default to occur. In other words, the probability of bankruptcy depends upon the distance between the current value of the firm's assets and the face value of its liabilities, adjusted for the expected growth in asset value relative to asset volatility.

It is assumed that the opportunity cost of bank debt holders (including both retail and wholesale investors) and equity holders is the risk-free rate, $R_{t}$. The returns for bank debt $\left(R_{t}^{d}\right)$ and equity $\left(R_{t}^{s}\right)$ are determined so that the expected returns for debt and equity holders are the same as their opportunity cost $r_{t}$,

$$
R_{t} D_{t}=R_{t}^{d}\left(1-\pi_{t}^{D}\right) D_{t}+R_{t}^{d} \pi_{t}^{D}\left(1-L G D_{t}\right) D_{t}
$$

\footnotetext{
${ }^{7}$ See Appendix A for a complete derivation.
} 


$$
R_{t} S_{t}=R_{t}^{s}\left(1-\pi_{t}^{D}\right) S_{t}
$$

where $L G D_{t}$ denotes the loss given default for the bank liability. The asset side of the intermediaries consists of business lending and household lending, thus the market clearing condition for the credit market is

$$
B_{t}^{e}+B_{t}^{\prime}=D_{t}+S_{t}
$$

We define $\kappa_{t}^{b}$ as the bank capital ratio, that is, $\kappa_{t}^{b}=S_{t} /\left(D_{t}+S_{t}\right)$. Then the funding cost of the bank $\left(R_{t}^{b}\right)$ is the weighted average of debt return and equity return, that is, $R_{t}^{b}=\left(1-\kappa_{t}^{b}\right) R_{t}^{d}+\kappa^{b} R_{t}^{s}$. Using the above relationships between the risk free rate and the debt and equity return, we obtain

$$
\frac{R_{t}^{b}}{R_{t}}=\frac{1-\kappa_{t}^{b}}{1-\pi_{t}^{D} L G D_{t}}+\frac{\kappa_{t}^{b}}{1-\pi_{t}^{D}} \equiv G\left(D D_{t}\right) .
$$

From equation (19), when the intermediary's leverage increases, the distance to default decreases and the probability of default rises. Then equation (20) shows that the bank spread, the ratio of the bank funding cost to the risk-free rate, increases. On the other hand, when the expected profitability of the bank asset $\left(=\mu_{V}-\sigma_{V}^{2} / 2\right)$ improves, the distance to default increases, the probability of default falls and the bank spread falls. This mechanism has a similarity with Gertler-Karadi mechanism for the banking sector, in a sense that the required return for the bank investment is determined by the intermediary's leverage or the degree of capitalization. We express the relationship between the bank spread and the distance to default in equation (20) in a log-linearized form

$$
\widehat{b s}_{t}=\chi^{f} \cdot \widehat{D D}_{t}+\hat{\varepsilon}_{t}^{b s}
$$

where $\widehat{b s}_{t}=\hat{R}_{t}^{b}-\hat{R}_{t}$. $\hat{\varepsilon}_{t}^{b s}$ captures the changes in the bank spread not explained by the distance to default, such as the loss given default that may be affected by the default cost.

The intermediary's assets consist of household and business loan, that is, $V_{t}=m \varepsilon_{t}^{d b t} E_{t} q_{t+1}^{h} H_{t}^{\prime}+$ $\left(Q_{t} K_{t}^{p}-N W_{t}\right)$. We simply assume the intermediary distance to default is a function of the expected housing price and the investment goods price, that is, $D D_{t}=H\left(E_{t} q_{t+1}^{h}, Q_{t}\right)$. Low expected housing price or investment goods price affects the intermediary's asset quality, lowers the equity value and distance to default of the intermediary. In a log-linearized form,

$$
\widehat{D D}_{t}=\rho^{d d} \widehat{D D}_{t-1}+\chi^{d d, H} E_{t} \hat{q}_{t+1}^{h}+\chi^{d d, Q} \hat{Q}_{t}+\hat{\varepsilon}_{t}^{d d}
$$

In equation (21), $\chi^{d d, H}$ and $\chi^{d d, Q}$ are the parameters that measure sensitivity of distance to default to the expected housing price or the investment goods price. $\varepsilon_{t}^{d d}$ is a shock to the financial intermediaries' balance sheets not explained by those prices.

Figure 2 plots the distance to default and interbank spread implied by the data using the 


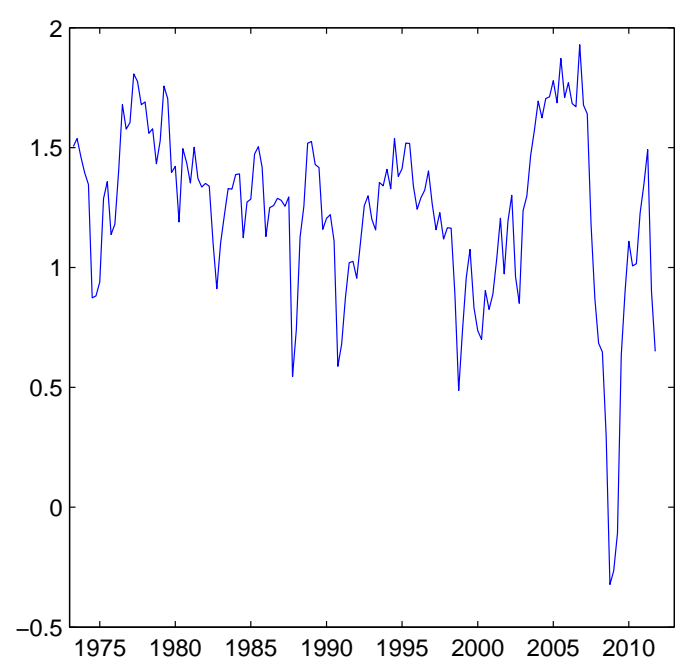

(a) Log (Distance to Default)

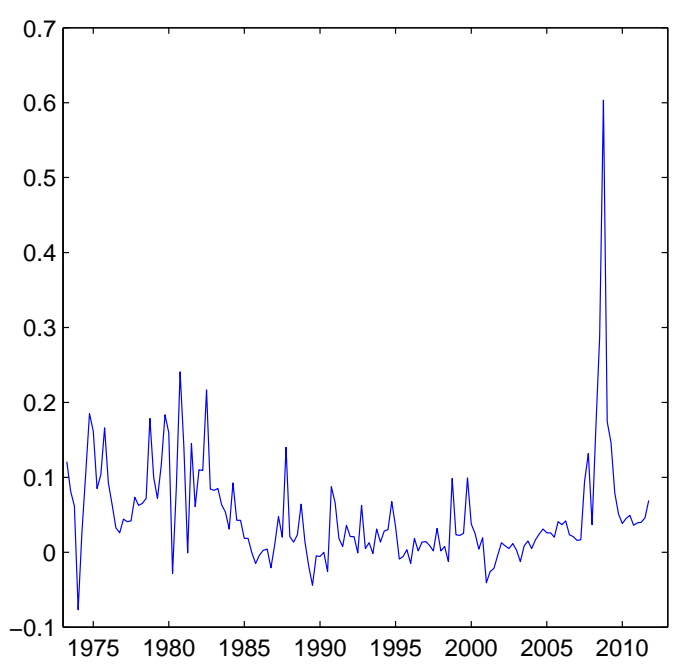

(b) Interbank Spread

Figure 2: Time series for distance to default and interbank spread

methodology of Carlson, King and Lewis (CKL). CKL focus on the 25 largest financial institutions by assets. ${ }^{8}$ They match the quarterly balance sheet data from Compustat for all the institutions to daily stock price data from CRSP. Using the entire stock price history of each firm from 1973 to year-end 2007, CKL calculate the expected probability of default on a daily basis using a well established methodology. ${ }^{9}$ CKL then extract the 25 largest firms, by assets, in each quarter and calculate their expected default probability. The median default probability of the top 25 firms is what we use in our estimation.

\section{Bayesian Estimation}

3.1 Estimation Method and Data As in the original SW model, we linearize the equilibrium conditions of the model around the balanced growth path steady-state. These equilibrium conditions, along with measurement equations for observable variables, constitute a state-space where the likelihood can be evaluated via the Kalman filter. We estimate structural parameters of the model using Bayesian methods. Given prior distributions of the parameters, we draw posterior distributions using the Metropolis-Hastings algorithm. ${ }^{10}$ Of the 350,000 draws, we dispose the first 140,000 and use the last 210,000 draws for the posterior distribution. There are 14 observable variables, 6 of them are identical to SW model. These are log differences in real GDP, GDP deflator, real consumption, real wage, log hours worked, and the federal funds rate. Investment is

\footnotetext{
${ }^{8}$ Financial institutions here comprise of depository institutions, non- depository credit institutions, securities and commodity brokers and dealers, and their hold- ing companies.

${ }^{9}$ The volatility of firm value is related to the volatility of equity according to $\sigma_{s}=(v / s) N(d) \sigma_{v}$. This equation and (17) can be used to solve for $V$ and $\sigma_{v}$ using stock price data (see Crosbie and Bohn (2003) for additional details).

${ }^{10}$ Dynare 4.2 is used for the posterior simulation.
} 
Table 1: Calibrated Parameters

\begin{tabular}{cll}
\hline Parameters & Description & Calibration \\
\hline$\delta$ & Depreciation rate, non-residential capital & 0.025 \\
$g_{y}$ & Government Spending-GDP ratio & 0.18 \\
$\lambda_{w}$ & Steady-state markup in the labor market & 1.5 \\
$\epsilon_{p}$ & Curvature, goods aggregation & 10 \\
$\epsilon_{w}$ & Curvature, labor aggregation & 10 \\
\hline$\delta_{h}$ & Depreciation rate, residential capital & 0.1 \\
$\mu$ & Labor income share, saving household & 0.75 \\
$m$ & Steady-state LTV ratio & 0.75 \\
$\psi$ & Weight on housing in the utility function & 0.15 \\
\hline
\end{tabular}

separated between residential and non-residential investment, and their log differences are used. We also use 6 additional observables related to the financial frictions of the model. These are the log difference of real household debt, real housing price index, log of banking sector distance to default and firm leverage, and the interbank interest rate spread between federal funds rate and one-month Euro-Dollar deposit rate ${ }^{11}$, and BAA-Treasury spread. Detailed description of data is provided in the appendix. The estimation sample period is from 1974:4 to 2011:4. ${ }^{12}$

3.2 Calibration Table 1 gives the values for calibrated parameters. We use the same calibration as SW with the addition of four new parameters. The depreciation rate of housing, $\delta_{h}$, is calibrated as 0.1 , greater than the depreciation rate of non-residential capital. $\psi$ represents the weight on housing in the utility function, and is chosen at 0.15 . These two calibrated parameters pin down the steady-state residential investment-nonresidential investment ratio at approximately $4: 1 . \mu$, the labor income share of saving household, is set at 0.75 , close to the estimate of Iacoviello and Neri (2010). $m$ is the steady-state LTV ratio of borrowing household and chosen at 0.75 , consistent with US data.

3.3 Prior and Posterior Distributions Tables 2 and 3 list the prior and posterior distributions of the estimated parameters. Most of the prior distributions are taken directly from the literature. The AR(1) and MA(1) coefficients, and for the correlation between output and government spending follows a beta distribution with a mean of 0.5 and a standard deviation of 0.2 . The prior distributions for the standard errors of the shocks follow an inverse gamma with a mean of 0.2 and a standard deviation of 2.0. The priors for the structural parameters from the original SW model are consistent with the SW model priors.

For the financial friction parameters, we examine two prior specifications. One specification

\footnotetext{
${ }^{11}$ Alternatively, one can consider the spread with the same maturity, for example, between three-month Euro-dollar deposit rate and Treasury Bill rate. However, we prefer federal funds rate to Treasury Bill rate because the former better represents monetary policy. Also, we use one-month Euro-Dollar deposit rate because no interbank rate with shorter maturity is available for our entire sample period. Our key results are preserved when we estimate the model using the spread between three-month Euro-dollar deposit rate and Treasury Bill rate.

${ }^{12}$ This is shorter than the original SW model due to the availability of additional data series.
} 
assumes a modest impact from the financial sector (weak prior), while the other assumes a much larger impact (strong prior). This allows us to examine the extent to which the posterior results are sensitive to prior specifications over financial friction parameters. A prior / posterior predictive analysis, conducted in the next section, allows us to accurately depict the extent to which the different prior specifications impacts our analysis both before and after estimation.

The strong priors are reported in parenthesis in Table 2. $\chi^{e}$ and $\chi^{f}$ are the elasticity of the entrepreneur external finance premium with regards to entrepreneur leverage and the bank spread to the bank distance to default, respectively. They represent the financial friction channel in the entrepreneurial sector and financial sector. The prior for $\chi^{e}$ and $\chi^{f}$ follows a normal distribution with a mean of $0.05(0.2),-0.05(-0.2)$, respectively, and a standard deviation of $0.02(0.05)$. The prior for $\chi^{d d, Q}$ and $\chi^{d d, H}$, the elasticity of distance to default with regards to investment goods price and housing price, is a normal distribution with a mean of $0.05(0.2)$ and a standard deviation of 0.02 (0.05). Finally, the prior for residential capital adjustment cost $\varphi^{h}$ and the steady-state housing price inflation $\bar{\pi}^{q h}$ is a normal distribution.

Tables 2 and 3 show the median, the mean, and the lower and upper bounds of 90 percent highest posterior density interval obtained by the Metropolis-Hastings algorithm. Somewhat surprising, observation is that the posterior distribution for the weak prior is nearly identical to that of the strong prior (in parenthesis). Imposing a more informative prior on the financial frictions seems to do very little to change posterior estimates. We expand on this observation in the next section.

The posterior mean for household preference parameters is 1.73 for the inverse elasticity of intertemporal substitution $\sigma_{c}$ (for the composite of consumption and housing goods), 2.05 for the inverse elasticity of labor $\sigma_{l}$ and 1.93 for the inverse elasticity between consumption goods and housing goods $\sigma_{h}$. Habit formation parameter $\lambda$ is estimated to be 0.54 , a little lower the original SW estimate. The posterior for the parameters in the production and price determination are similar to the original SW model. They include non-residential capital adjustment cost $\varphi$, capitallabor share of production function $\alpha$, fixed cost in production $\Phi$, price rigidity $\xi_{p}$. The posterior mean for the wage rigidity $\xi_{w}$ and wage indexation $\iota_{w}$ is estimated to be 0.93 and 0.52 , respectively. In the monetary policy rule, introducing financial friction induces a lower posterior mean value for the long-run reaction coefficient to inflation $r_{\pi}(=1.40)$, output gap $r_{y}(=0.00)$, compared to their SW model estimates of $1.87,0.07$. The trend growth rate $\gamma$ is estimated to be slightly lower than the SW model at 0.39 , and the steady-state inflation rate $\bar{\pi}$, real housing price appreciation rate $\bar{\pi}^{q h}$, and discount rate $\bar{\beta}$ are about 3.4 percent, 0.9 percent and 1.0 percent on an annual basis.

Regarding the financial frictions, distance to default is affected by the price of capital and expected housing price, as the posterior distribution for $\chi^{d d, Q}$ and $\chi^{d d, H}$ lies mostly in the positive range. However, the financial accelerator channel and the friction within the financial sector are not clear during the sample period, as the $90 \%$ credible regions for $\chi^{e}$ and $\chi^{f}$ contain both positive and negative values. Nevertheless, the mean and median for both parameters have the sign that is expected by the respective friction.

Among the estimated processes for the exogenous shock variables, productivity shock $\varepsilon^{a}$, gov- 
Table 2: Prior and posterior distribution of structural parameters

\begin{tabular}{|c|c|c|c|c|c|c|c|c|c|}
\hline & & & & cior Distribu & ion & & Posterior I & istribution & \\
\hline & & & Distr. & Mean & St.Dev. & Median & Mean & HPD inf & HPD sup \\
\hline & $\varphi$ & Non-residential capital adjustment cost & Normal & 4.00 & 1.50 & $5.37(5.37)$ & $5.40(5.38)$ & $3.67(3.70)$ & $7.03(7.07)$ \\
\hline & $\sigma_{c}$ & Elasticity of intertemporal substitution & Normal & 1.50 & 0.37 & $1.73(1.72)$ & $1.73(1.73)$ & $1.50(1.50)$ & $1.99(1.95)$ \\
\hline & $\lambda$ & Habit formation & Beta & 0.70 & 0.10 & $0.54(0.54)$ & $0.54(0.54)$ & $0.48(0.48)$ & $0.60(0.60)$ \\
\hline & $\xi_{w}$ & Wage rigidity & Beta & 0.50 & 0.10 & $0.93(0.93)$ & $0.93(0.93)$ & $0.90(0.90)$ & $0.95(0.95)$ \\
\hline & $\sigma_{l}$ & Labor elasticity & Normal & 2.00 & 0.75 & $2.03(2.01)$ & $2.05(2.04)$ & $1.16(1.12)$ & $2.96(2.94)$ \\
\hline & $\xi_{p}$ & Price rigidity & Beta & 0.50 & 0.10 & $0.80(0.81)$ & $0.80(0.81)$ & $0.74(0.74)$ & $0.87(0.87)$ \\
\hline & $\iota_{w}$ & Wage indexation & Beta & 0.50 & 0.15 & $0.53(0.51)$ & $0.52(0.51)$ & $0.30(0.28)$ & $0.75(0.72)$ \\
\hline & $\iota_{p}$ & Price indexation & Beta & 0.50 & 0.15 & $0.20(0.21)$ & $0.21(0.22)$ & $0.09(0.09)$ & $0.33(0.34)$ \\
\hline & $\Psi$ & Capital Utilization & Beta & 0.50 & 0.15 & $0.76(0.75)$ & $0.76(0.74)$ & $0.62(0.59)$ & $0.90(0.90)$ \\
\hline & $\Phi$ & Fixed cost in production & Normal & 1.25 & 0.12 & $1.54(1.54)$ & $1.54(1.55)$ & $1.40(1.41)$ & $1.68(1.68)$ \\
\hline & $r_{\pi}$ & MP reaction to inflation & Normal & 1.50 & 0.25 & $1.39(1.39)$ & $1.40(1.41)$ & $1.21(1.23)$ & $1.59(1.59)$ \\
\hline & $\rho$ & MP rigidity & Beta & 0.75 & 0.10 & $0.80(0.80)$ & $0.80(0.80)$ & $0.76(0.76)$ & $0.84(0.84)$ \\
\hline$\vec{\perp}$ & $r_{y}$ & MP reaction to output gap & Normal & 0.12 & 0.05 & $0.00(0.00)$ & $0.00(0.00)$ & $-0.01(-0.01)$ & $0.01(0.01)$ \\
\hline & $r_{\Delta_{y}}$ & MP reaction to output gap change & Normal & 0.12 & 0.05 & $0.21(0.20)$ & $0.21(0.21)$ & $0.17(0.16)$ & $0.25(0.25)$ \\
\hline & $\bar{\pi}$ & Steady-state inflation & Gamma & 0.62 & 0.10 & $0.84(0.84)$ & $0.84(0.84)$ & $0.65(0.65)$ & $1.03(1.03)$ \\
\hline & $\bar{\beta}$ & Steady-state discount rate & Gamma & 0.25 & 0.10 & $0.25(0.23)$ & $0.25(0.24)$ & $0.12(0.11)$ & $0.38(0.37)$ \\
\hline & $\bar{l}$ & Steady-state hours worked & Normal & 0.00 & 2.00 & $-2.03(-2.06)$ & $-2.03(-2.06)$ & $-4.84(-4.41)$ & $0.48(0.38)$ \\
\hline & $\bar{\gamma}$ & Steady-state trend growth rate & Normal & 0.40 & 0.10 & $0.40(0.40)$ & $0.39(0.40)$ & $0.32(0.34)$ & $0.45(0.45)$ \\
\hline & $\alpha$ & Capital share in production & Normal & 0.30 & 0.05 & $0.15(0.15)$ & $0.15(0.15)$ & $0.13(0.13)$ & $0.18(0.18)$ \\
\hline & $\varphi^{h}$ & Residential capital adjustment cost & Normal & 0.30 & 0.05 & $0.27(0.27)$ & $0.27(0.27)$ & $0.23(0.23)$ & $0.31(0.31)$ \\
\hline & $\sigma^{h}$ & Elasticity, consumption and housing & Normal & 1.50 & 0.37 & $1.93(1.92)$ & $1.93(1.93)$ & $1.54(1.57)$ & $2.33(2.29)$ \\
\hline & $\bar{\pi}^{q h}$ & Steady-state housing price inflation & Normal & 0.2 & 0.15 & $0.22(0.22)$ & $0.22(0.22)$ & $0.16(0.16)$ & $0.28(0.28)$ \\
\hline & $\chi^{e}$ & Financial accelerator & Normal & $0.05(0.2)$ & $0.02(0.05)$ & $0.003(0.003)$ & $0.004(0.003)$ & $-0.004(-0.004)$ & $0.01(0.01)$ \\
\hline & $\chi^{f}$ & Bank spread elasticity to DD & Normal & $-0.05(-0.2)$ & $0.02(0.05)$ & $-0.02(-0.03)$ & $-0.02(-0.04)$ & $-0.05(-0.10)$ & $0.01(0.02)$ \\
\hline & $\chi^{d d, Q}$ & DD elasticity to capital price & Normal & $0.05(0.2)$ & $0.02(0.05)$ & $0.01(0.01)$ & $0.01(0.01)$ & $0.00(0.00)$ & $0.02(0.01)$ \\
\hline & $\chi^{d d, H}$ & DD elasticity to housing price & Normal & $0.05(0.2)$ & $0.02(0.05)$ & $0.01(0.01)$ & $0.01(0.01)$ & $0.00(0.00)$ & $0.01(0.01)$ \\
\hline
\end{tabular}

Note: The table shows posterior estimates from both weak and strong financial friction priors. Posterior estimates from strong financial friction prior are in parenthesis. 
Table 3: Prior and posterior distribution of shock processes

\begin{tabular}{|c|c|c|c|c|c|c|c|c|}
\hline & & \multicolumn{3}{|c|}{ Prior Distribution } & \multicolumn{4}{|c|}{ Posterior Distribution } \\
\hline & & Distr. & Mean & St.Dev. & Median & Mean & HPD Inf & HPD Sup \\
\hline$\sigma_{a}$ & SE, productivity & Invgam & 0.10 & 2.00 & $0.42(0.42)$ & $0.42(0.42)$ & $0.37(0.38)$ & $0.46(0.46)$ \\
\hline$\sigma_{\beta}$ & SE, discount factor & Invgam & 0.10 & 2.00 & $0.31(0.30)$ & $0.31(0.31)$ & $0.24(0.24)$ & $0.39(0.38)$ \\
\hline$\sigma_{g}$ & SE, government & Invgam & 0.10 & 2.00 & $0.46(0.46)$ & $0.46(0.46)$ & $0.41(0.41)$ & $0.50(0.51)$ \\
\hline$\sigma_{I}$ & SE, investment & Invgam & 0.10 & 2.00 & $0.41(0.41)$ & $0.41(0.41)$ & $0.33(0.33)$ & $0.48(0.49)$ \\
\hline$\sigma_{r}$ & SE, monetary & Invgam & 0.10 & 2.00 & $0.24(0.24)$ & $0.24(0.24)$ & $0.21(0.21)$ & $0.27(0.27)$ \\
\hline$\sigma_{p}$ & SE, inflation markup & Invgam & 0.10 & 2.00 & $0.13(0.13)$ & $0.13(0.13)$ & $0.11(0.11)$ & $0.16(0.15)$ \\
\hline$\sigma_{w}$ & SE, wage markup & Invgam & 0.10 & 2.00 & $0.29(0.29)$ & $0.29(0.29)$ & $0.25(0.24)$ & $0.33(0.33)$ \\
\hline$\sigma_{b s}$ & SE, bank spread & Invgam & 0.10 & 2.00 & $0.06(0.06)$ & $0.06(0.06)$ & $0.06(0.06)$ & $0.07(0.07)$ \\
\hline$\sigma_{d d}$ & $\mathrm{SE}$, distance to default & Invgam & 0.10 & 2.00 & $0.20(0.20)$ & $0.20(0.20)$ & $0.18(0.18)$ & $0.22(0.22)$ \\
\hline$\sigma_{r p}$ & $\mathrm{SE}$, risk premium & Invgam & 0.10 & 2.00 & $0.09(0.09)$ & $0.09(0.09)$ & $0.08(0.08)$ & $0.10(0.10)$ \\
\hline$\sigma_{n w}$ & $\mathrm{SE}$, net worth $\times 10$ & Invgam & 0.10 & 2.00 & $0.20(0.20)$ & $0.20(0.20)$ & $0.18(0.18)$ & $0.22(0.22)$ \\
\hline$\sigma_{a h}$ & SE, housing investment $\times 10$ & Invgam & 0.10 & 2.00 & $0.19(0.19)$ & $0.19(0.19)$ & $0.17(0.17)$ & $0.21(0.21)$ \\
\hline$\sigma_{\psi}$ & SE, housing demand $\times 10$ & Invgam & 0.10 & 2.00 & $0.61(0.61)$ & $0.61(0.61)$ & $0.52(0.53)$ & $0.70(0.70)$ \\
\hline$\sigma_{d b t}$ & SE, lending standard $\times 10$ & Invgam & 0.10 & 2.00 & $0.27(0.27)$ & $0.27(0.27)$ & $0.24(0.24)$ & $0.30(0.30)$ \\
\hline$\rho_{a}$ & $\mathrm{AR}(1)$, productivity & Beta & 0.50 & 0.20 & $0.98(0.98)$ & $0.98(0.98)$ & $0.97(0.97)$ & $0.99(0.99)$ \\
\hline$\rho_{\beta}$ & $\mathrm{AR}(1)$, discount factor & Beta & 0.50 & 0.20 & $0.69(0.69)$ & $0.69(0.70)$ & $0.53(0.53)$ & $0.87(0.87)$ \\
\hline$\rho_{g}$ & $\mathrm{AR}(1)$, government & Beta & 0.50 & 0.20 & $0.98(0.99)$ & $0.98(0.98)$ & $0.96(0.96)$ & $0.99(0.99)$ \\
\hline$\rho_{I}$ & $\mathrm{AR}(1)$, investment & Beta & 0.50 & 0.20 & $0.78(0.78)$ & $0.78(0.78)$ & $0.71(0.72)$ & $0.85(0.85)$ \\
\hline$\rho_{r}$ & $\operatorname{AR}(1)$, monetary & Beta & 0.50 & 0.20 & $0.16(0.17)$ & $0.17(0.17)$ & $0.05(0.07)$ & $0.28(0.28)$ \\
\hline$\rho_{p}$ & $\operatorname{AR}(1)$, inflation markup & Beta & 0.50 & 0.20 & $0.91(0.91)$ & $0.91(0.90)$ & $0.85(0.84)$ & $0.97(0.97)$ \\
\hline$\rho_{w}$ & $\operatorname{AR}(1)$, wage markup & Beta & 0.50 & 0.20 & $0.81(0.76)$ & $0.75(0.73)$ & $0.46(0.46)$ & $0.97(0.97)$ \\
\hline$\rho_{b s}$ & $\mathrm{AR}(1)$, bank spread & Beta & 0.50 & 0.20 & $0.73(0.76)$ & $0.73(0.75)$ & $0.62(0.59)$ & $0.85(0.91)$ \\
\hline$\rho_{d d}$ & $\operatorname{AR}(1)$, distance to default & Beta & 0.50 & 0.20 & $0.95(0.95)$ & $0.95(0.95)$ & $0.90(0.91)$ & $0.99(0.99)$ \\
\hline$\rho_{r p}$ & $\mathrm{AR}(1)$, risk premium & Beta & 0.50 & 0.20 & $0.97(0.97)$ & $0.97(0.97)$ & $0.94(0.95)$ & $0.99(0.99)$ \\
\hline$\rho_{n w}$ & $\operatorname{AR}(1)$, net worth & Beta & 0.50 & 0.20 & $0.43(0.42)$ & $0.44(0.43)$ & $0.28(0.26)$ & $0.60(0.58)$ \\
\hline$\rho_{a h}$ & $\mathrm{AR}(1)$, housing investment & Beta & 0.50 & 0.20 & $0.97(0.97)$ & $0.97(0.97)$ & $0.95(0.95)$ & $0.99(0.99)$ \\
\hline$\rho_{\psi}$ & $\operatorname{AR}(1)$, housing demand & Beta & 0.50 & 0.20 & $0.97(0.97)$ & $0.97(0.97)$ & $0.95(0.95)$ & $0.99(0.99)$ \\
\hline$\rho_{d b t}$ & $\mathrm{AR}(1)$, lending standard & Beta & 0.50 & 0.20 & $0.99(0.99)$ & $0.99(0.99)$ & $0.99(0.99)$ & $0.99(0.99)$ \\
\hline$\mu_{p}$ & MA(1), inflation markup & Beta & 0.50 & 0.20 & $0.81(0.81)$ & $0.80(0.79)$ & $0.69(0.67)$ & $0.91(0.91)$ \\
\hline$\mu_{w}$ & MA(1), wage markup & Beta & 0.50 & 0.20 & $0.77(0.71)$ & $0.70(0.67)$ & $0.36(0.33)$ & $0.97(0.96)$ \\
\hline$\rho_{g y}$ & Government spending correlation & Beta & 0.50 & 0.20 & $0.49(0.49)$ & $0.48(0.49)$ & $0.35(0.34)$ & $0.62(0.64)$ \\
\hline
\end{tabular}

Note: The table shows posterior estimates from both weak and strong financial friction priors. Posterior estimates from strong financial friction prior are in parenthesis. 
ernment spending shock $\varepsilon^{g}$, housing investment shock $a^{h}$, housing demand shock $\varepsilon^{\psi}$, risk premium shock $\varepsilon^{r p}$ and lending standard shock $\varepsilon^{d b t}$ are strongly persistent, with posterior mean AR (1) coefficients over 0.95 . The discount factor shock $\varepsilon^{\beta}$ is estimated to have a higher standard error compared to the financial friction shock in the SW model.

\section{Results}

4.1 Prior-Posterior Predictive Analysis We echo Geweke (2005), Faust and Gupta (2012) and Leeper et al. (2011) in arguing for the use of prior and posterior predictive analysis to shed light on the black-box nature of empirically validated DSGE models. Our objects of interest are the standard deviations of changes in output $\left(\sigma_{\Delta Y}\right)$, consumption $\left(\sigma_{\Delta C}\right)$, investment $\left(\sigma_{\Delta I}\right)$, and the correlation between changes in consumption and investment $\left(\rho_{(\Delta C, \Delta I)}\right)$. The standard deviations help us verify the amplification channel and additional volatility attributable to the financial frictions (Brunnermeier et al. (2012)). The correlation helps us to assess whether the model can generate the comovement between consumption and investment that was readily apparent during the financial crisis. To sample predictive distributions, first we simulate 175,000 sets of prior and posterior parameter draws from the SW-FF and SW models. Then for each set of draws, we obtain the statistics of interest from the simulated time series of 400 periods.

Figures 3-6 present the prior and posterior predictive densities for chosen statistics of interest. Panel (a) of figure 3 is the prior predictive density of the standard deviation of the change in output $\left(\sigma_{\Delta Y}\right)$. The SW-FF model with more informative prior (strong prior) has a distribution centered to the right relative to the SW model or SW-FF model with weak prior. For example, standard deviation value of 2 percent or higher is very unlikely from the SW or SW-FF with weak prior, but the SW-FF with strong prior assigns more probability to the range. Panel (b) of figure 3 reports the posterior predictive density from each model specification. The posterior predictive density from the SW-FF is more dispersed and centered to the right relative to the SW model. However, the strong and weak prior specifications have identical posterior distributions, suggesting a more dogmatic prior geared towards substantially larger output volatility is not borne out in the data.

Figures 4 and 5 are the prior-posterior predictive densities for the standard deviation of the change in aggregate consumption $\left(\sigma_{\Delta C}\right)$ and investment $\left(\sigma_{\Delta I}\right)$. Disappointingly, although in theory the impatient household's borrowing constraint in the SW-FF model can amplify consumption volatility, the model's prior predictive density does not show noticeable difference with the SW model regarding consumption volatility. Only the posterior density demonstrates higher consumption volatility for the SW-FF model, to a degree comparable to the output volatility case.

By contrast, the financial frictions clearly help the model match the substantial volatility in investment that is typical of business cycles. For example, the realized change in investment in quarter one of 2009 was $-10.41 \%$. The SW model places negligible probability of such an event, while the strong prior SW-FF model allows for such volatility (standard deviation value of $5 \%$ or more is not unlikely). The posterior analysis shows that including financial frictions leads to a standard deviation that is more in line with the great recession. However, the differences are not 


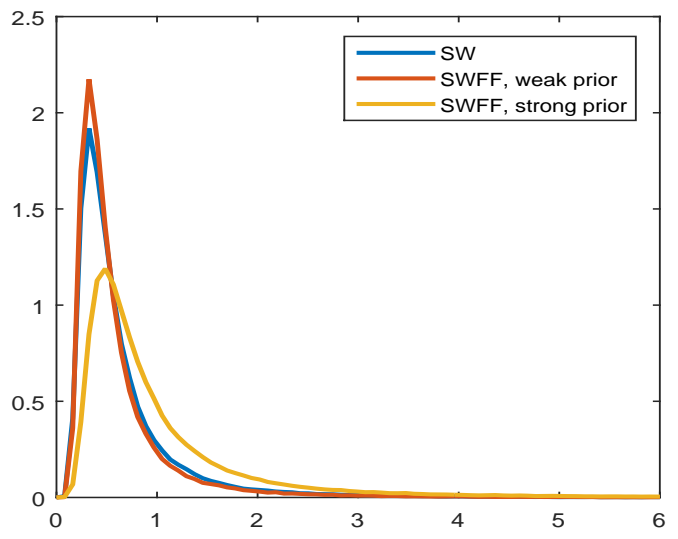

(a) Prior predictive distribution

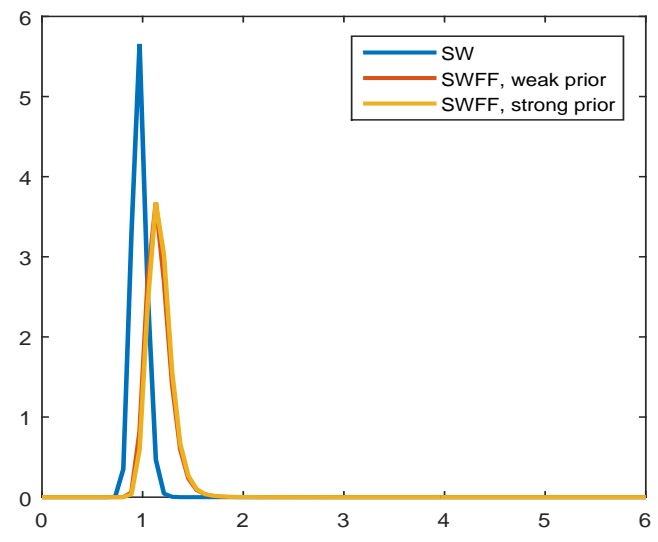

(b) Posterior predictive distribution

Figure 3: Prior-posterior predictive distribution, standard deviation ( $\Delta$ Output)

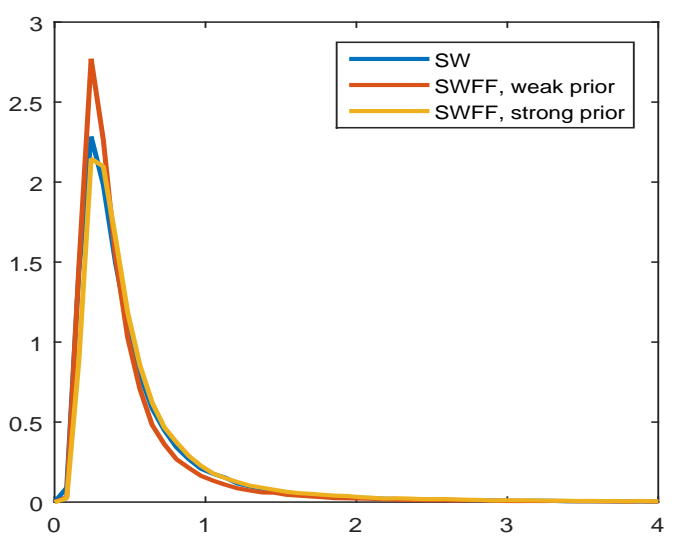

(a) Prior predictive distribution

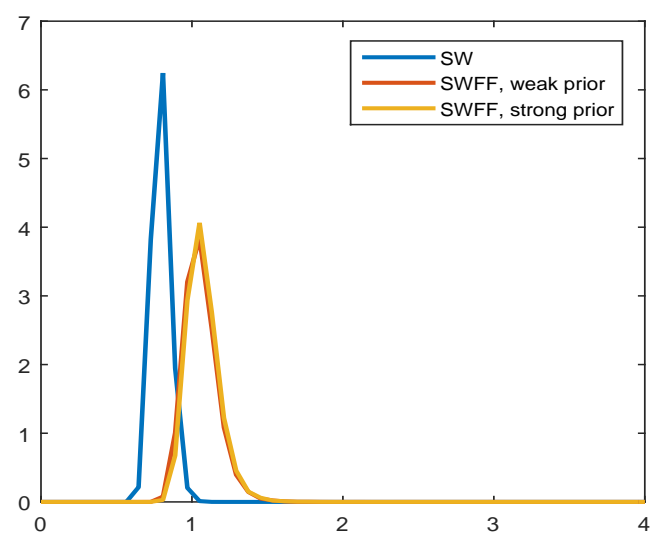

(b) Posterior predictive distribution

Figure 4: Prior-posterior predictive distribution, standard deviation ( $\Delta$ Consumption) 


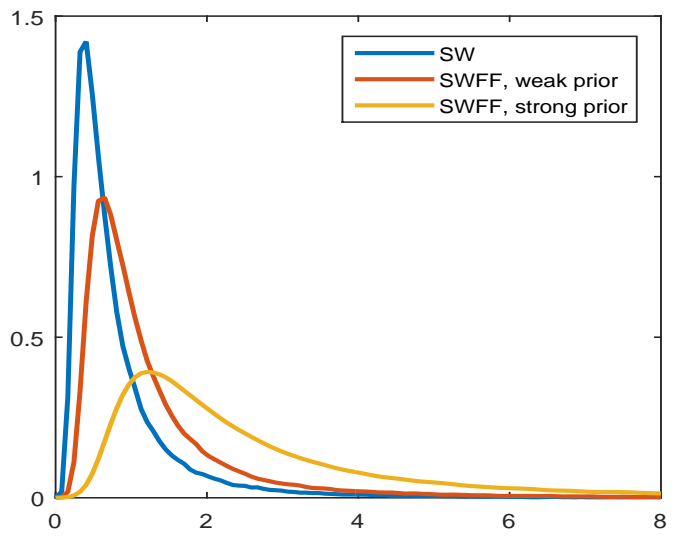

(a) Prior predictive distribution

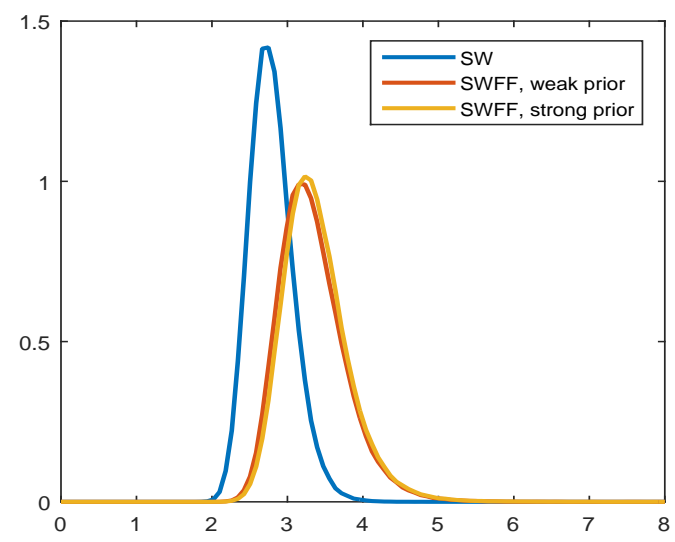

(b) Posterior predictive distribution

Figure 5: Prior-posterior predictive distribution, standard deviation ( $\Delta$ Investment)

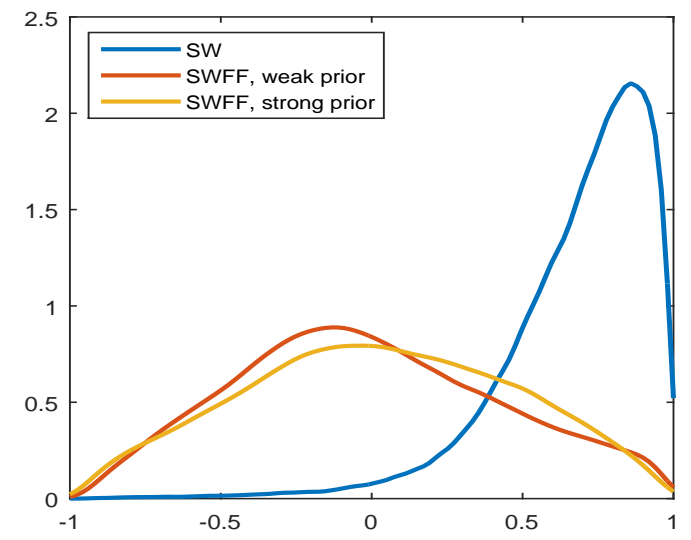

(a) Prior predictive distribution

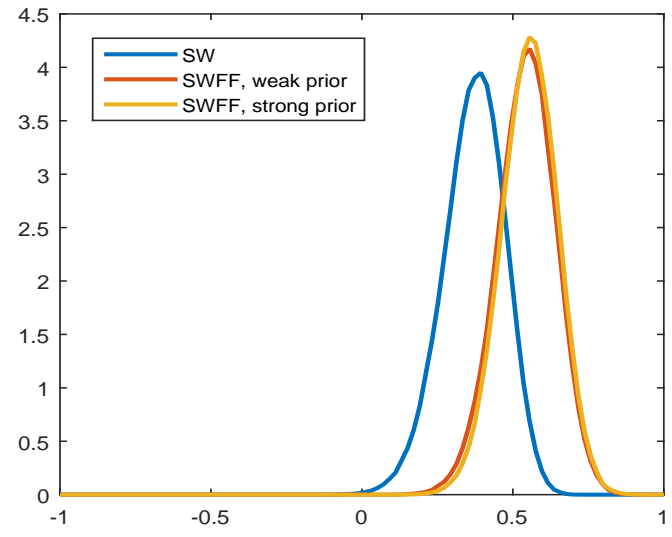

(b) Posterior predictive distribution

Figure 6: Prior-posterior predictive distribution, correlation ( $\Delta$ Investment- $\Delta$ consumption)

as stark as the prior may suggest.

Figure 6 is the prior-posterior predictive densities for the correlation between in consumption and investment $\left(\rho_{(\Delta C, \Delta I)}\right)$. Prior predictive density for the SW model is more concentrated pointing to high correlation value. However, posterior densities reveal that it is the SW-FF model that presents higher correlation. The realized correlation during the sample period is 0.41 , and the posterior predictive from SW and SW-FF model have similar density for this value.

The message delivered by this predictive analysis is somewhat mixed. First, SW-FF model with strong prior shows better promise in predicting severe financial crises. However, posterior predictive distributions show that the differences between the models are mitigated substantially by the data. This suggests that it is not likely that the SW-FF can offer substantially improved predictive power. One potential reason for this is that recessions as large as the Great Recession are relatively rare events. Most of the data used to fit and compare these models comes from the 

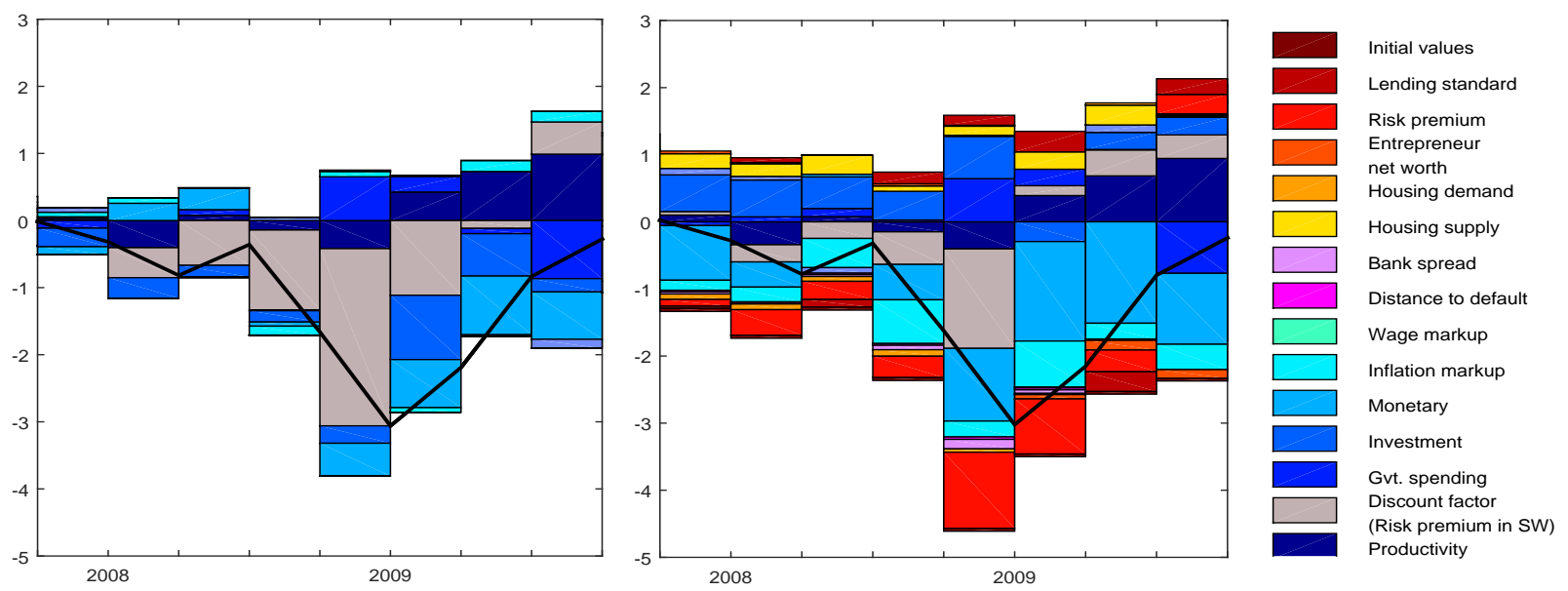

Figure 7: Historical decomposition (SW model-left, SW-FF model-right), changes in output, deviation from trend $(\%)$

era of Great Moderation. Hence the data will not assign a large role to the financial frictions. This explains why the SW and SW-FF models do not look substantially different when taken to data.

\subsection{Historical Decomposition: How Does the Model Interpret 2007-2009 Financial} CRISIS? We now examine how the 2007-2009 financial crisis is interpreted by SW-FF and SW models. Figures 7 - 9 compare the historical decompositions of the changes in output, consumption and investment for the two models. As already mentioned in Section 2, in SW model, the financial friction shock is the most important determinant of the recession during 2008:3 - 2009:1. It accounts for the majority of the downfall in consumption, investment and thus output. By design, a large financial friction shock can generate significant comovement between consumption and investment because it enters into the optimal intertemporal decision regarding both consumption and investment. Along with the financial friction shock, the investment efficiency shock is an important factor for the investment decrease in SW model.

In SW-FF model, shocks related to financial friction, most notably the risk premium shock, play a significant role in the recession. The investment decrease is mostly driven by the risk premium shock. The bank spread shock and net worth shock are also important, albeit their contribution is not as big. Regarding the risk premium shock, the biggest difference between investment efficiency shock and risk premium shock is that while the former is a shock to the capital supply, the latter is a shock to the capital demand by affecting the funding condition of entrepreneurs. Therefore, the latter provides a better explanation of the comovement between investment and the asset (capital) price during the crisis, consistent with the findings of Christiano et al. (2014).

An important criterion to assess the model's ability to explain the financial crisis is whether it can generate a simultaneous drop in consumption and investment. Figures 8 and 9 show that in 

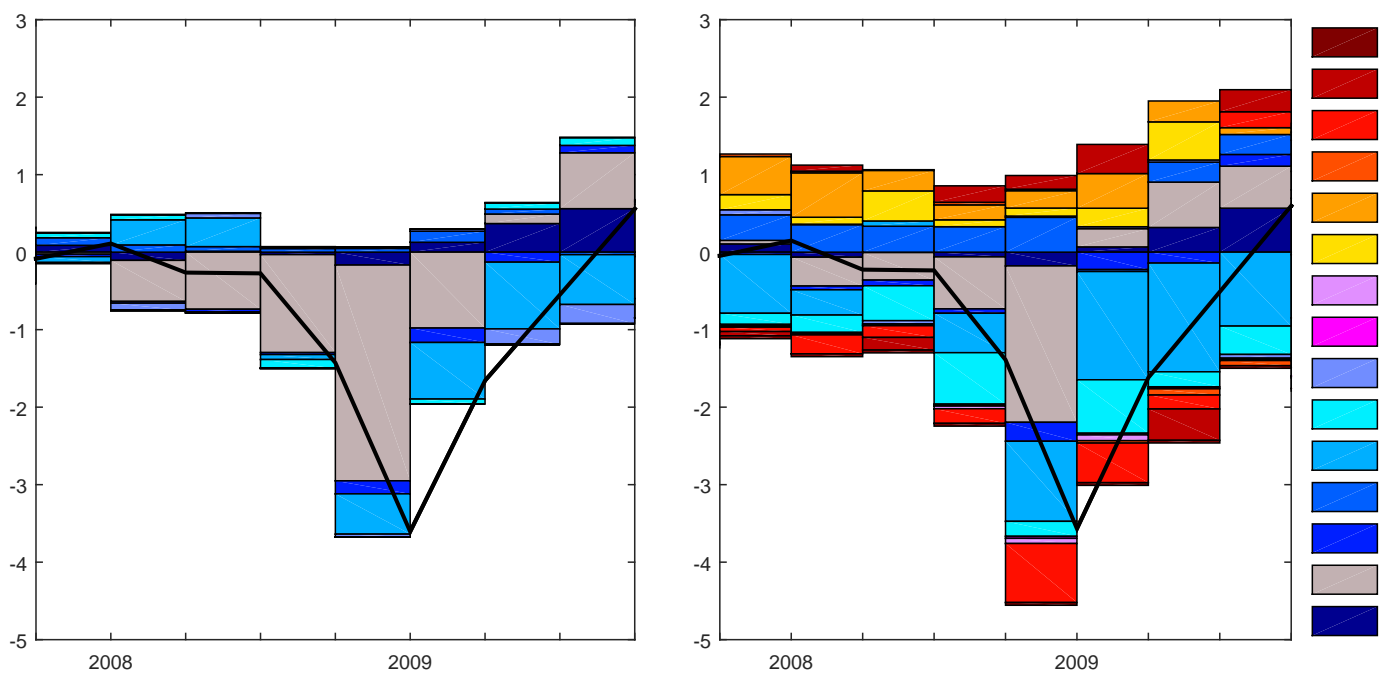

Initial values

Lending standard

Risk premium

Entrepreneur

net worth

Housing demand

Housing supply

Bank spread

Distance to default

Wage markup

Inflation markup

Monetary

Investment

Gvt. spending

Discount factor

(Risk premium in SW)

Productivity

Figure 8: Historical decomposition (SW model-left, SW-FF model-right), changes in consumption, deviation from trend $(\%)$
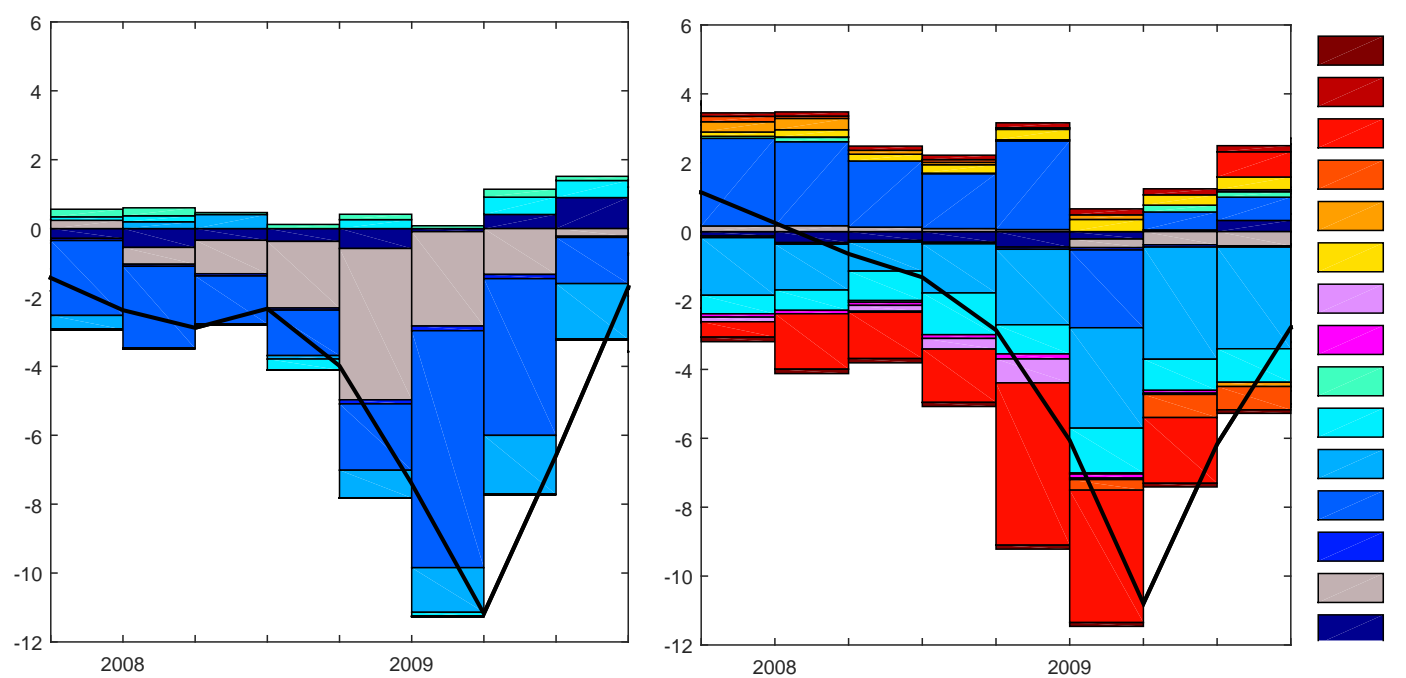

Initial values

Lending standard

Risk premium

Entreprenuer

net worth

Housing demand

Housing supply

Bank spread

Distance to defualt

Wage markup

Inflation markup

Monetary

Investment

Gvt. spending

Discount factor

(Risk premium in SW)

Productivity

Figure 9: Historical decomposition (SW model-left, SW-FF model-right), changes in investment, deviation from trend (\%) 


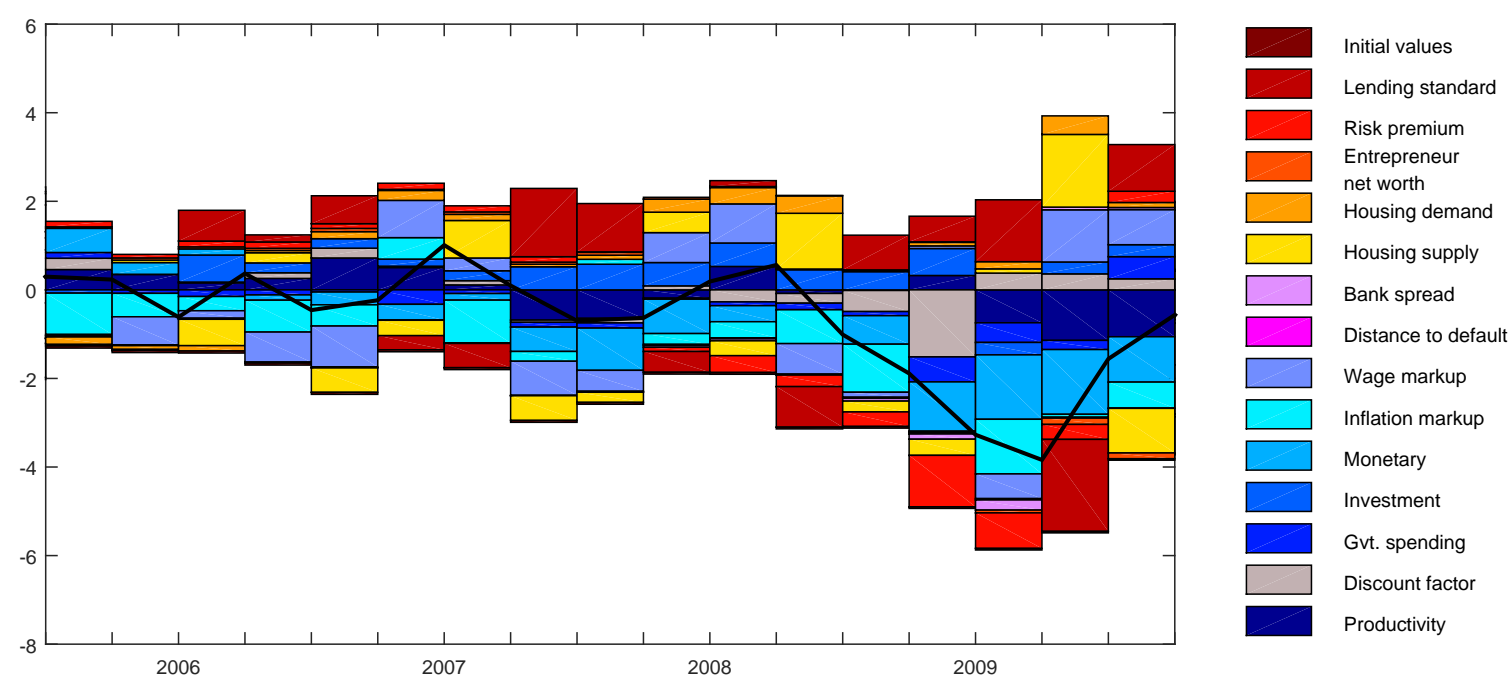

Figure 10: Historical decomposition (SW-FF model), changes in consumption, credit constrained households, deviation from trend (\%)

the SW-FF model, although a large fraction of investment decrease is explained by risk premium shock and other financial shocks, consumption decrease is mostly driven by discount factor shock, monetary policy shock and inflation markup.

Can this be seen as an evidence that the link between financial frictions and household consumption is still weak? The supposed link between them in the model is the credit-constrained household. Financial conditions affect credit-constrained households directly through two channels. First, a fall in housing price induces their LTV constraint to bind more tightly, resulting in a reduction in consumption. Second, changes in bank spread determines the rate they can borrow from financial intermediaries. Figure 10 shows the historical decomposition of the changes in credit constrained households' consumption. While risk premium shock, bank spread shock and housing supply shock contribute to consumption decrease, it is still discount factor shock, monetary policy shock and inflation markup shock that accounts for the largest part. Moreover, given the calibrated size of credit constrained households (one fourth of total households), these effects from financial friction are likely to be diluted in total consumption. ${ }^{13}$ The contribution of lending standard shock is in fact positive until the second quarter of 2009 when it swings to a large negative value, as it reflects the rising LTV ratio that is typical when asset price is falling.

\footnotetext{
${ }^{13}$ Christiano et al. (2014) claims that risk shock can explain the comovement between consumption and investment. But in their model capital is determined by households, not entrepreneurs, creating an arbitrage condition between risk-free bond and capital by households. This assumption, along with another assumption that capital functions not as a saving instrument but as a borrowing instrument in their model, can strengthen comovement. However, we do not adopt those assumptions because they mute entrepreneur's role in investment, violating the original assumption by Bernanke et al. (1999), and they are not realistic descriptions of household decision.
} 
4.3 'Balance Sheet' vs. 'Non-Balance Sheet' Channels of Financial Friction The 2007-2009 financial crisis is regarded as an example that demonstrates systemic nature of financial crises. Before the crisis, periods of credit expansion had led to excessive borrowing of households and high risk exposure of the banking sector. Once housing prices began to drop, households found themselves insolvent and the banking sector capital deteriorated. A collapse of the banking sector led to a credit crunch, feeding negative effects back to household and business sector.

Can we identify this systemic channel using the SW-FF model? For this purpose, let us classify net worth shock, housing shock and distance-to-default shock as 'balance sheet' shocks, and risk premium shock, bank spread shock as 'spread' shocks. Balance sheet shocks can change borrowers' balance sheet conditions, reflecting such events as unexpected revaluation in asset qualities. Therefore, this class of shocks can explain balance sheet or structural channel of financial friction in which the borrowers' ability to finance is affected by their balance sheet strength. On the other hand, spread shocks can change the risk premia given balance sheet conditions, reflecting market sentiment mainly about future volatility. For example, as is emphasized by Christiano et al. (2014), changes in the volatility of idiosyncratic productivity distribution can be a source of this type of shocks.

Figures 11 - 14 show that while shocks related to financial frictions play a significant role for the crisis, the 'balance sheet' channel of financial friction does not appear to be strong. The net worth shock and distance to default shock account for a majority of firm net worth and financial intermediary distance to default decreases, but their contribution to the risk spread (BAA-Tresury) and bank spread is weak. It follows that their contribution to consumption or investment must also be weak, because the risk spread and bank spread are the direct channels that financial conditions affect non-financial agent decisions.

Spread shocks account for the majority of risk spread and bank spread, and their impact on consumption and investment is larger accordingly. Several explanations are possible for this underrepresentation of the balance sheet channel of financial friction in this model. First, the nonlinear nature of financial frictions is not captured by this linearized model. This can lead to an underestimation of the propagation mechanism that balance sheet shocks have on the credit intermediation. Second, it is possible that this balance sheet channel has been indeed weak during the estimation sample period, except a few periods around the financial crisis. That can result in smaller estimates of parameters that account for the propagation, in the financial accelerator $\left(\chi^{e}\right)$ or in the bank spread $\left(\chi^{f}\right)$. In Section 5.5, we discuss this possibility in further detail using sequential posterior estimates of financial friction parameters. Third, there is a delay in the balance sheet data, as for accounting reasons operational or capital losses can be realized after the period is over. This can cause the realization of balance sheet shocks to lag behind the business cycle, rather than to lead it.

4.4 Variance Decomposition Variance decompositions show how much a shock contributes to the forecast error variance of each variable. We use variance decomposition to understand the importance of each financial friction channel in the model. Tables 4 and 5 present the variance 


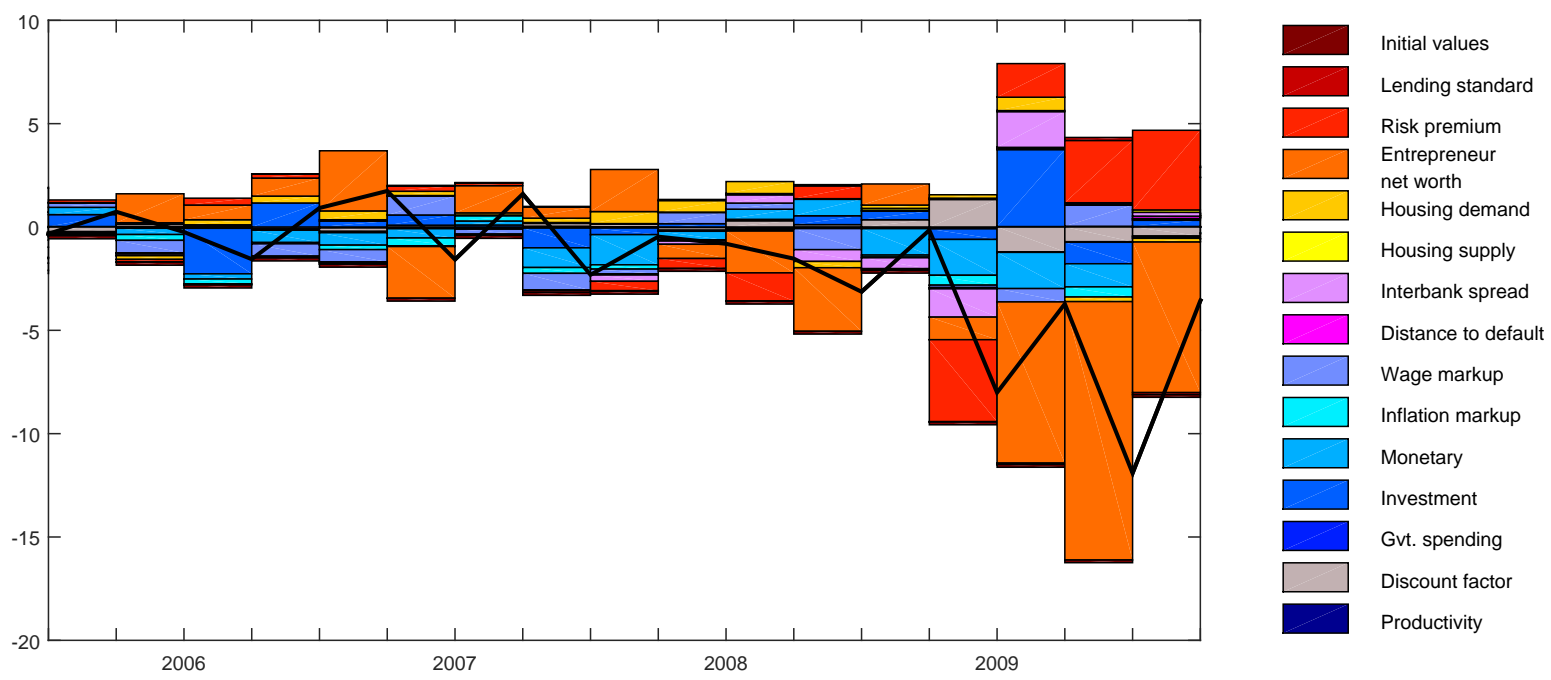

Figure 11: Historical decomposition (SW-FF model), changes in net worth, deviation from trend $(\%)$
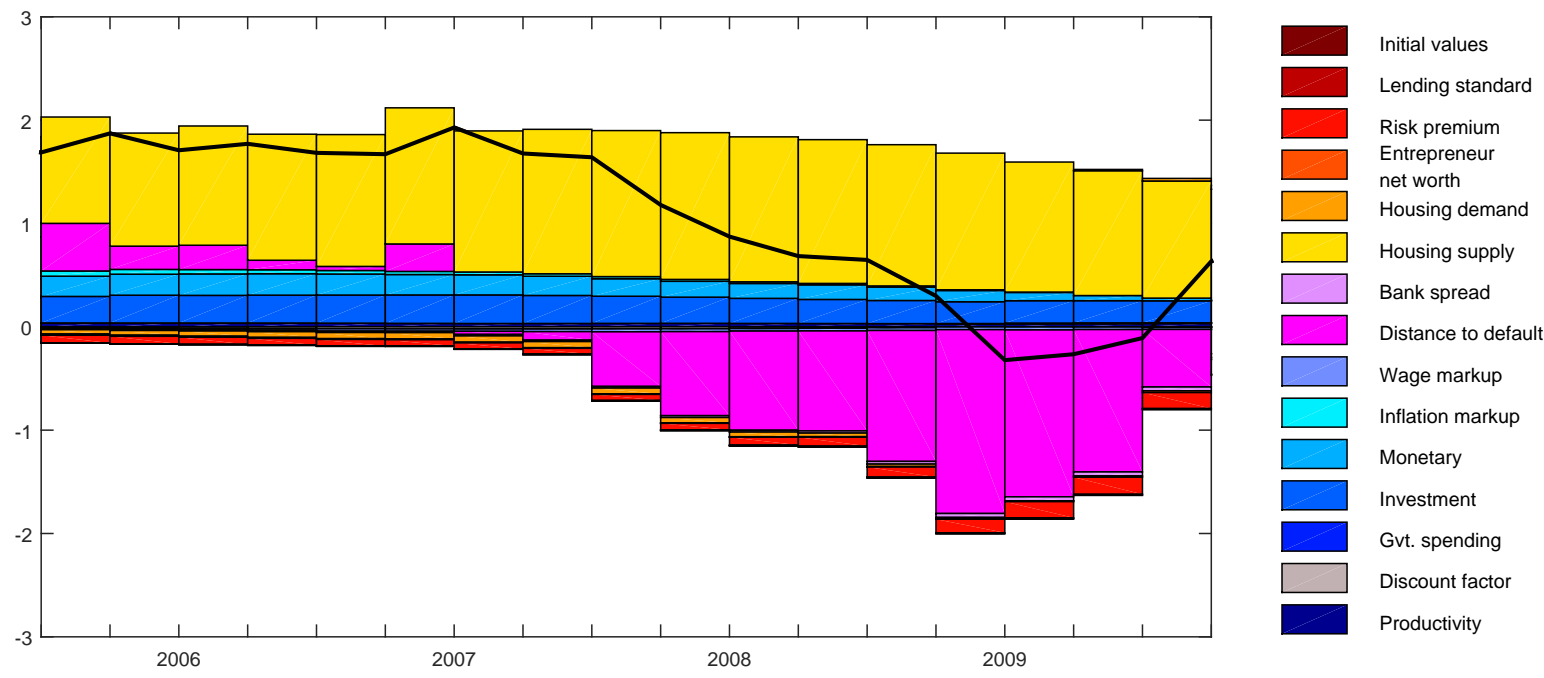

Figure 12: Historical decomposition (SW-FF model), distance-to-default, logged value 


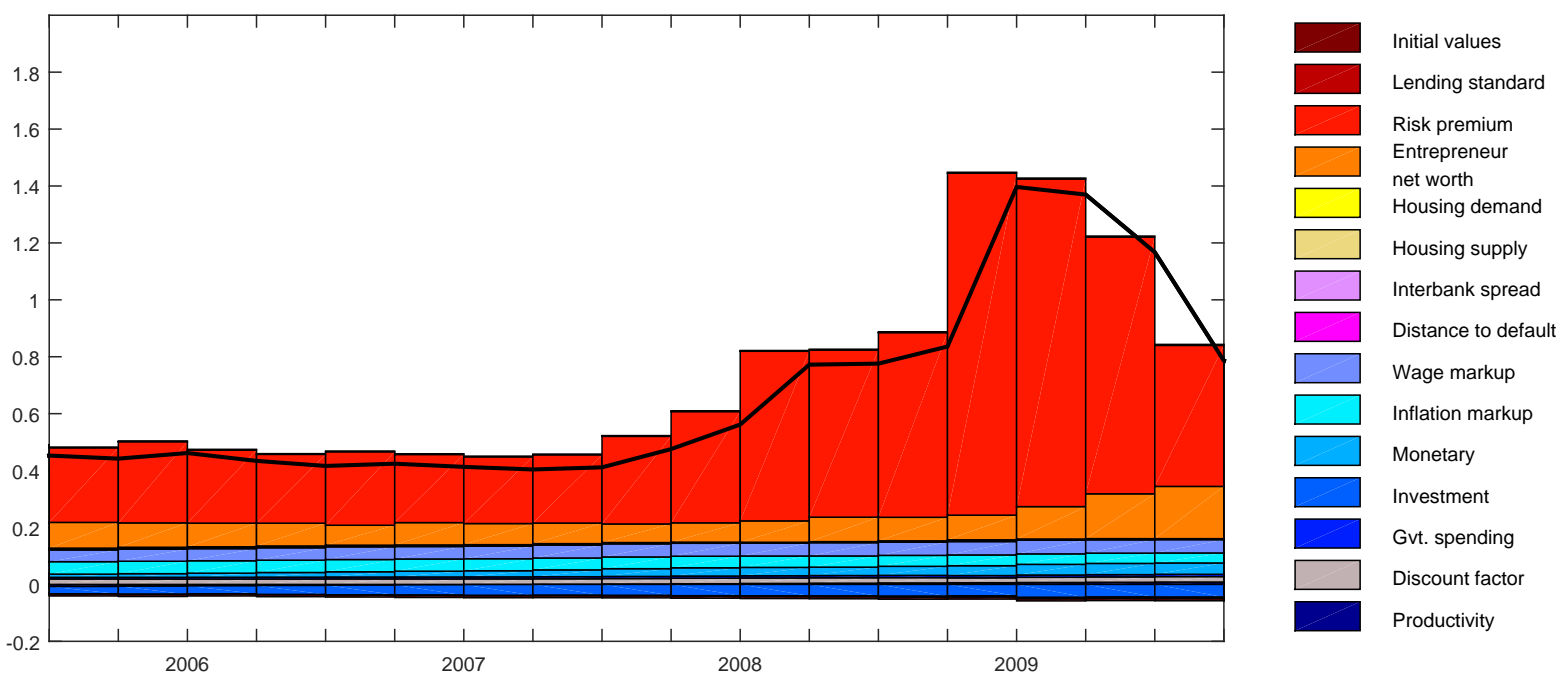

Figure 13: Historical decomposition (SW-FF model), risk spread (\%)

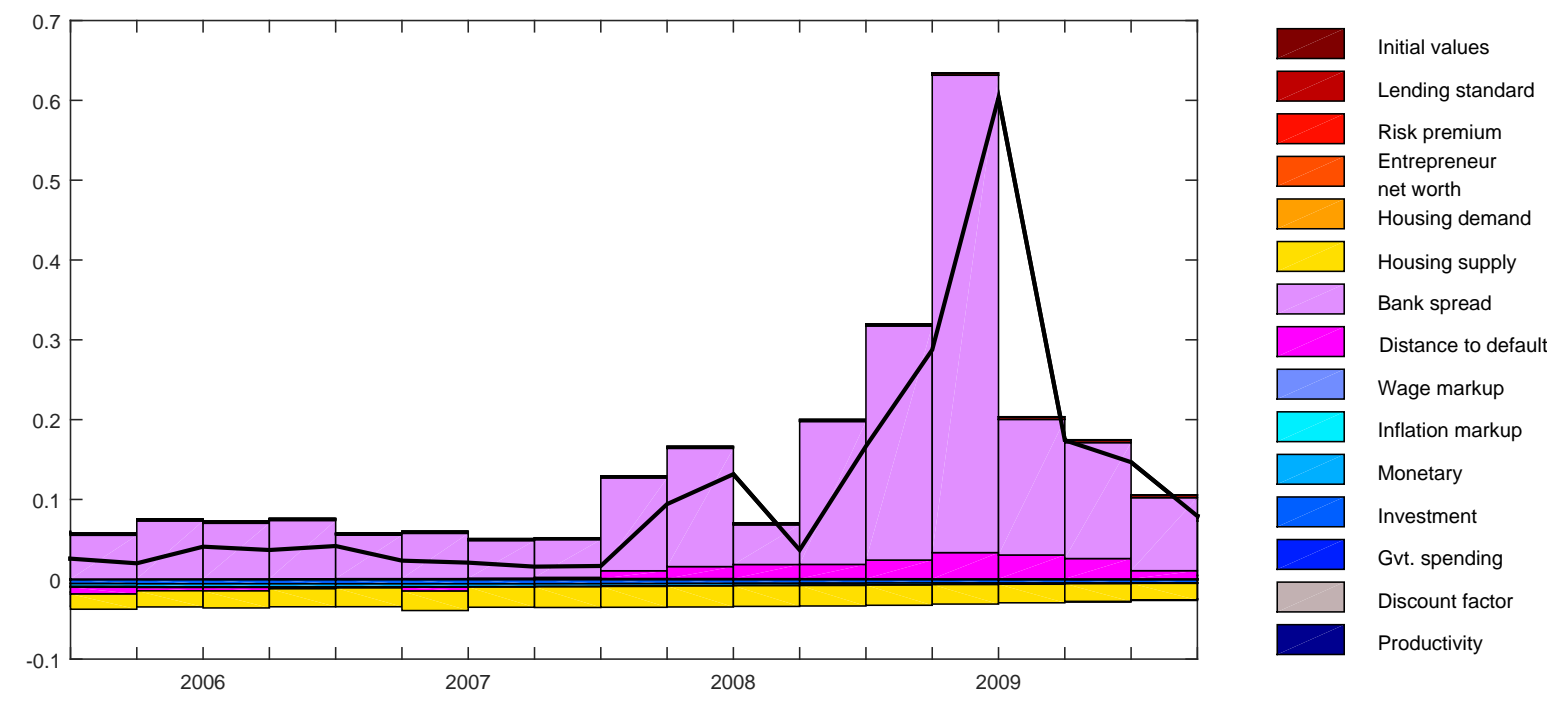

Figure 14: Historical decomposition (SW-FF model), bank spread (\%) 
Table 4: Variance decomposition, financial variables (\%)

\begin{tabular}{l|rrrr}
\hline Variables & \multicolumn{1}{c}{$\begin{array}{c}\text { Entrepreneur } \\
\text { risk spread }\end{array}$} & $\begin{array}{c}\text { Entrepreneur } \\
\text { leverage }\end{array}$ & $\begin{array}{c}\text { Bank } \\
\text { spread }\end{array}$ & $\begin{array}{c}\text { Distance to } \\
\text { default }\end{array}$ \\
\hline Risk premium & $93.6(95.4)$ & $44.1(47.7)$ & $0.0(0.1)$ & $0.7(0.6)$ \\
Entrepreneur net worth & $3.5(2.4)$ & $30.1(26.8)$ & $0.0(0.0)$ & $0.0(0.0)$ \\
Bank spread & $0.0(0.0)$ & $0.0(0.0)$ & $96.4(88.3)$ & $0.0(0.0)$ \\
Distance to default & $0.0(0.0)$ & $0.0(0.0)$ & $1.5(5.0)$ & $41.3(43.1)$ \\
Non-financial & $2.9(2.9)$ & $25.8(25.4)$ & $2.1(6.6)$ & $58.7(56.3)$ \\
\hline
\end{tabular}

Note: The table shows posterior estimates from both weak and strong financial friction priors. Posterior estimates from strong financial friction prior are in parenthesis.

Table 5: Variance decomposition, non-financial variables (\%)

\begin{tabular}{|c|c|c|c|c|c|c|}
\hline Variables & $\Delta$ Output & $\Delta$ Consumption & $\Delta$ Investment & Inflation & $\begin{array}{l}\text { Housing } \\
\text { inflation }\end{array}$ & $\begin{array}{l}\Delta \text { Housing } \\
\text { investment }\end{array}$ \\
\hline Productivity & $9.5(8.7)$ & $4.5(3.9)$ & $1.5(1.5)$ & $19.8(19.5)$ & $0.4(0.3)$ & $1.4(1.3)$ \\
\hline Discount factor & $11.7(11.7)$ & $26.6(26.4)$ & $0.9(0.9)$ & $0.8(0.8)$ & $1.1(1.1)$ & $1.6(1.7)$ \\
\hline Gvt. spending & $10.9(10.7)$ & $1.7(1.7)$ & $0.0(0.0)$ & $3.0(2.8)$ & $0.3(0.3)$ & $0.8(0.8)$ \\
\hline Inv. specific & $22.3(22.8)$ & $11.7(12.1)$ & $65.0(64.4)$ & $7.3(7.6)$ & $0.2(0.2)$ & $1.0(1.1)$ \\
\hline Monetary & $21.3(21.0)$ & $24.0(23.6)$ & $8.2(8.0)$ & $1.9(1.9)$ & $8.7(8.7)$ & $18.6(18.6)$ \\
\hline Inflation markup & $11.4(11.7)$ & $12.7(12.9)$ & $8.4(8.5)$ & $33.3(32.8)$ & $0.3(0.4)$ & $2.2(2.3)$ \\
\hline Housing demand & $0.2(0.2)$ & $4.5(4.6)$ & $0.2(0.2)$ & $4.7(4.5)$ & $25.6(25.3)$ & $64.4(64.1)$ \\
\hline Housing supply & $1.2(1.1)$ & $2.0(2.0)$ & $0.1(0.1)$ & $0.7(0.7)$ & $62.3(62.6)$ & $8.2(8.2)$ \\
\hline Risk premium & $6.9(7.6)$ & $5.0(5.7)$ & $13.6(14.3)$ & $8.5(9.7)$ & $0.1(0.2)$ & $0.4(0.5)$ \\
\hline Other financial & $2.6(2.5)$ & $5.0(4.8)$ & $0.5(0.5)$ & $0.4(0.3)$ & $0.9(0.9)$ & $0.8(0.8)$ \\
\hline
\end{tabular}

Note: The table shows posterior estimates from both weak and strong financial friction priors. Posterior estimates from strong financial friction prior are in parenthesis.

decomposition of financial and non-financial variables at the posterior mean. Table 4 shows that financial shocks (risk premium shock, net worth shock, bank spread shock, and distance to default shock) explain a large part of the forecast error variance of financial indicator variables (risk spread, entrepreneur leverage, bank spread, distance to default). Non-financial shocks explain about 26 percent of entrepreneur leverage and 59 percent of distance to default, but only less than 5 percent of risk spread and bank spread. However, table 5 shows that the effects of financial shocks on nonfinancial variable are limited. Only risk premium shock has a significant contribution (14 percent of investment and 7 percent of output). These results from variance decomposition again indicate that the role of financial friction in the estimated model, especially balance sheet channel, is not strong.

4.5 Sequential Estimation As mentioned in the introduction, one possible explanation for why the financial frictions do not play a more significant role in the analysis is that the degree of financial friction may vary over time. The financial crisis represents a small component of our overall sample. Estimates for parameters governing financial frictions may not be prominent due to time averaging over the entire sample.

To assess this possible time variation, we sequentially estimate the model parameters using 15year rolling windows with annual steps. That is, we estimate the posteriors using the sample from 1975:1q-1989:4q, then step forward and re-estimate the posteriors using 1976:1q-1990:4q, and so 


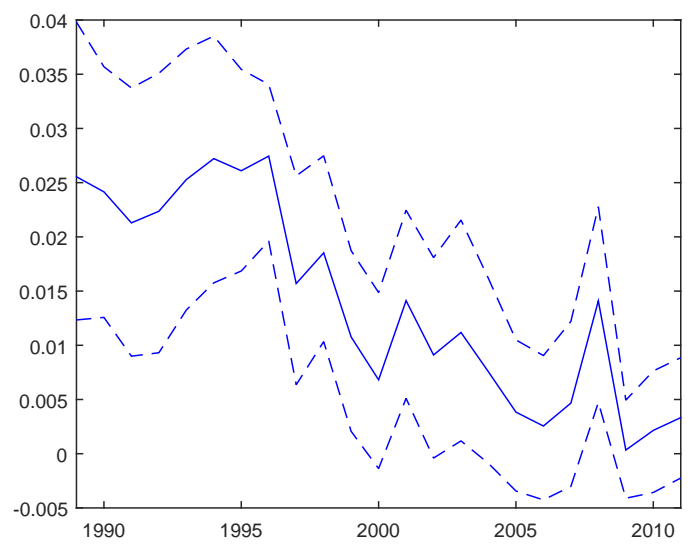

(a) $\chi^{e}$, elasticity of entrepreneur external finance premium to leverage

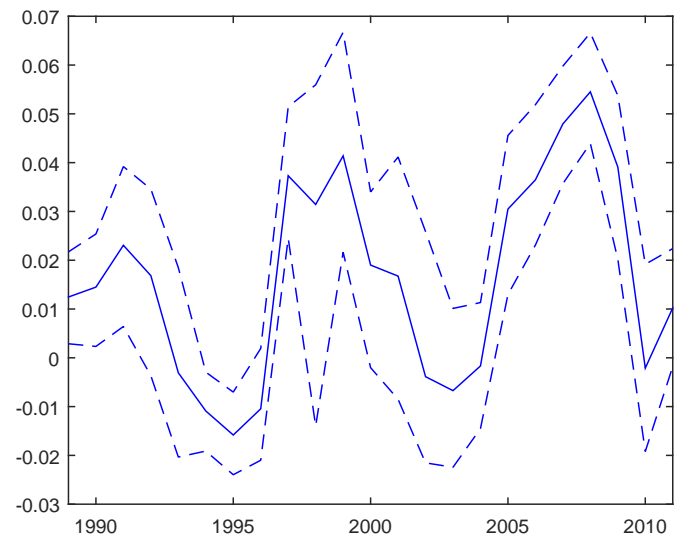

(c) $\chi^{d d, H}$, elasticity of distance to default to expected housing price

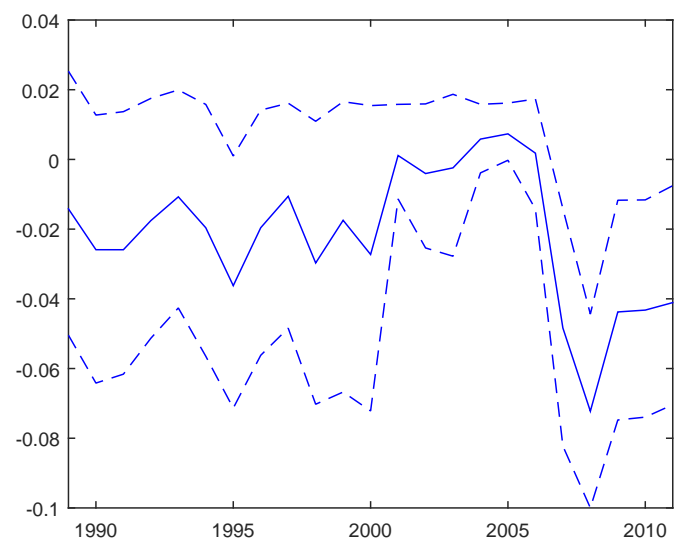

(b) $\chi^{f}$, elasticity of bank spread to distance to default

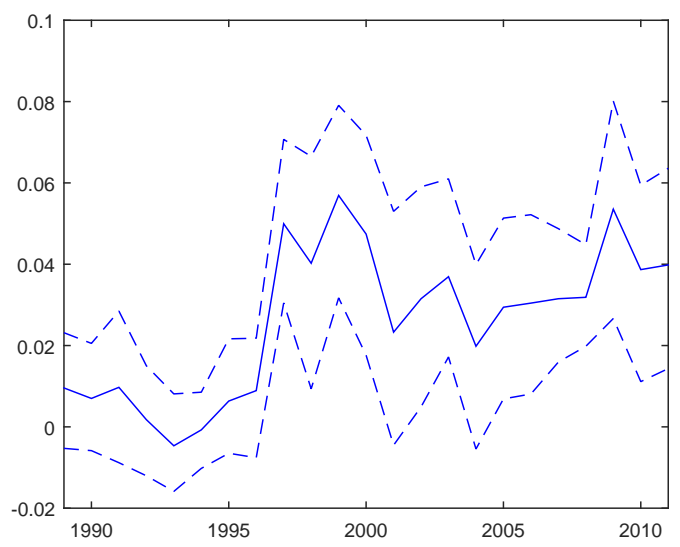

(d) $\chi^{d d, Q}$, elasticity of distance to default to investment goods price

Note: The solid lines are mean values and dashed lines are 90\% credible intervals. Posteriors are estimated from 15-year rolling windows using data 1975:1q - 1989:4q through 1997:1q-2011:4q.

Figure 15: Sequential posterior estimates for financial friction parameters.

on. In this way, we can obtain 23 windows from 1975:1q-1989:4q to 1997:1q-2011:4q. This thought experiment is an indication of the extent of time variation in important parameter values. Figure 15 presents the posterior mean and $90 \%$ credible sets of key financial friction parameters in our model, the elasticity of entrepreneur external finance premium to leverage $\left(\chi^{e}\right)$, elasticity of bank spread to distance to default $\left(\chi^{f}\right)$, elasticity of distance to default to expected housing price $\left(\chi^{d d, H}\right)$ and elasticity of distance to default to investment goods price $\left(\chi^{d d, Q}\right)$.

The figure indeed supports that there is substantial time variation in the degree of financial frictions. Specifically, the balance sheet channel becomes much more intense during the financial crisis. The elasticity of the entrepreneur external finance premium with respect to leverage $\left(\chi^{e}\right.$, panel a) shows diminishing trend, but elevates quickly during the financial crisis. The posterior 
median for the entire sample, reported in Table 4, is 0.003 for both the strong and weak financial friction prior. This value is roughly in the 95th percentile of the left tail of the parameter distribution centered around the financial crisis. The large spike around 2008 has a median value of 0.016 or roughly a five-fold increase relative to the posterior median for the entire sample.

The elasticity of the bank funding cost with respect to the bank distance to default $\left(\chi^{f}\right.$, panel b) shows little trend until the early 2000s, when it increases to a positive median value. (Recall a negative value indicates a financial friction.) This parameter quickly becomes large and negative when the rolling estimate includes the financial crisis. The median value of the full-sample posterior is -0.02 (-0.03) for the weak (strong) prior. The rolling-window median estimate of -0.07 is several standard deviations away from the full-sample posterior median but largely inconsistent with the strong prior assumption.

The elasticity of the bank distance to default with regards to expected housing prices and capital price ( $\chi^{d d, H}$ panel c and $\chi^{d d, Q}$ panel d, respectively), also display clear time variation. Both increase in the late 1990s, drop over the early 2000s and then spike around the financial crisis. Obviously, balance sheet channels become more intensified during the financial crisis as both parameters reach a maximum over this sub-sample. These spikes, however, cannot be identified in the estimates using the entire sample.

Our rolling-sample results support the argument that balance-sheet channel parameters are smoothed over the entire sample and would be underestimated vis-a-vis a nonlinear model (e.g., regime-switching in financial parameters). However while the financial friction parameters vary dramatically over the sub-samples, the model remains incapable of explaining important features of the Great Recession. For example, figure 16 plots the standard deviation of consumption and investment over two samples-the full sample (1975:2011) and the subsample that includes the financial crisis (1995:2009). While the posterior volatility of consumption increases substantially during the subsample containing the crisis, the change in volatility of investment is nearly negligible. This is prima facie evidence that even a non-linear version of the model is incapable of explaining important elements of the crisis (e.g., the drop in investment).

\subsection{Alternative Approaches The previous section suggests that time variation in parameter} values is a likely explanation for why the linearized model with financial frictions does not fit the data well. We offer three other possibilities and discuss how one might go about implementing or at least testing for these alternative scenarios. First, as discussed in the introduction, it is possible that our model does not account for the financial crisis well because it is omitting the key frictions (and data) responsible for the crisis. Our model does not incorporate bank runs-specifically, runs on shadow banks [Gorton and Metrick (2009), Morris and Shin (2008), Brunnermeier and Sannikov (2014)]. Angeloni and Faia (2013), Angeloni et al. (2014) and Angeloni et al. (2015) introduce bank runs as a propagation mechanism. These models are able to explain the large recession associated with the financial crisis. However, these models have yet to be subjected to the rigorous empirical testing advocated in this paper. If these models are to become workhorses, they should be estimated carefully and shown to fit data well. 

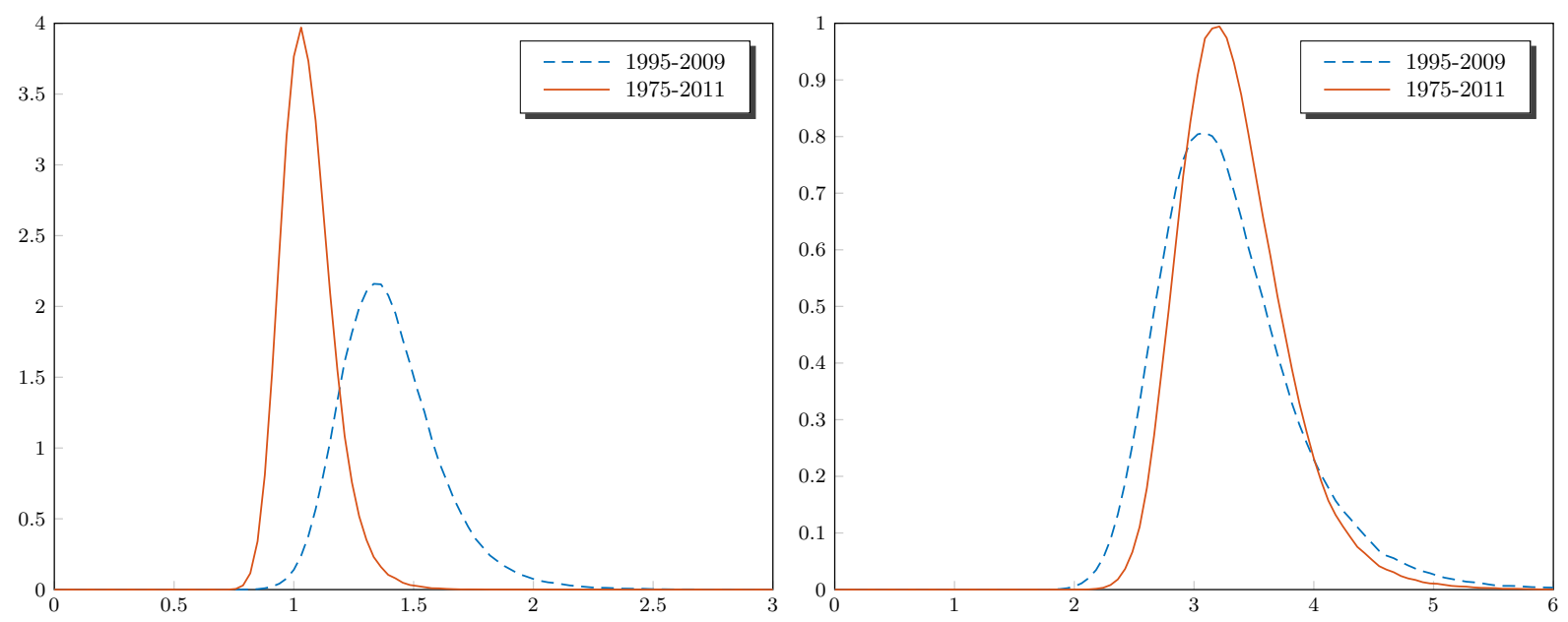

(a) Standard deviation of changes in consumption (b) Standard deviation of changes in investment for for 1975:2011 (solid) and 1995:2009 (dashed). $\quad$ 1975:2011 (solid) and 1995:2009 (dashed).

Figure 16: Sequential posterior estimates standard deviation of changes in consumption and investment for the full sample (1975:2011) versus a subsample (1995:2009).

Second, Del Negro et al. (2014) show how prediction pools can be used effectively to capture the nonlinear effects of the great recession. Using linear models with and without financial frictions (similar to those employed here), Del Negro et al. (2014) show that a dynamic prediction pool that places different weights on models with and without financial frictions is an effective way to capture the time-varying nature of the parameters documented in Section 4.5. They use out-ofsample prediction as a metric to determine model usefulness. They find that the data strongly prefer the model with financial frictions during the great recession and the model without frictions during the great moderation period.

Finally, combining several macroeconomic and econometric models (e.g., VARs, dynamic factor models, DSGE models) has been shown to improve forecast accuracy [Amisano and Geweke (2013)]. If the goal is simply to better forecast macro aggregates, Amisano and Geweke (2013) argue that a combination approach — where each econometric approach is given equal weight — vastly outperforms stand-alone models and standard Bayesian model averaging.

\section{Conclusion}

We set up a DSGE model with various financial frictions, and use it to interpret 2007-2009 financial crisis. Predictive analysis shows that the model can produce larger amplification mechanism compared with standard DSGE model without financial friction. Risk premium shock, a shock to the external finance premium given entrepreneurs' leverage, accounts for a significant fraction of investment decrease during the financial crisis. However, the balance sheet channel of financial friction does not appear strong in the model, contradicting to the common notion about what happened during the crisis. This can be regarded as limitations to the approaches to graft financial frictions into DSGE models. 
Our paper offers some direction for future work. First, further efforts need to be made to incorporate non-linear aspects of financial frictions into business cycle models. While we find important nonlinearities in the data, accounting for those may not be sufficient for fitting large recessions, especially in investment. Second, models with endogenous default may be better enabled to fit data. However, more work needs to be done to empirically test these models in a rigorous fashion. Finally, we need to understand non-balance sheet channels of financial frictions (e.g., bank runs), especially considering it can be a key to explain the comovement between investment and consumption during the financial crisis.

\section{REFERENCES}

Adrian, T. And H. Shin (2010): "Financial Intermediaries and Monetary Economics," in Handbook of Monetary Economics, ed. by B. M. Friedman and M. Woodford, Elsevier, vol. 3 of Handbook of Monetary Economics, chap. 12, 601-650.

Amisano, G. And J. Geweke (2013): "Prediction using several macroeconomic models," Working Paper Series 1537, European Central Bank.

Angeloni, I. And E. FAia (2013): "Capital regulation and monetary policy with fragile banks," Journal of Monetary Economics, 60, 311-324.

Angeloni, I., E. Faia, And M. Lo Duca (2015): "Monetary policy and risk taking," Journal of Economic Dynamics and Control, 52, 285-307.

Angeloni, I., E. Faia, And R. Winkler (2014): "Exit strategies," European Economic Review, $70,231-257$.

Bernanke, B. S., M. Gertler, and S. Gilchrist (1999): "The financial accelerator in a quantitative business cycle framework," Elsevier, vol. 1 of Handbook of Macroeconomics, 13411393.

Black, F. And M. S. Scholes (1973): "The Pricing of Options and Corporate Liabilities," Journal of Political Economy, 81, 637-54.

Brunnermeier, M. K., T. M. Eisenbach, And Y. Sannikov (2012): "Macroeconomics with Financial Frictions: A Survey," NBER Working Papers.

Brunnermeier, M. K. And Y. SAnnikov (2014): "A Macroeconomic Model with a Financial Sector," American Economic Review, 104, 379-421.

Brzoza-Brzezina, M. And M. Kolasa (2013): "Bayesian Evaluation of DSGE Models with Financial Frictions," Journal of Money, Credit and Banking, 45, 1451-1476.

Carlson, M. A., T. King, And K. Lewis (2011): "Distress in the Financial Sector and Economic Activity," The B.E. Journal of Economic Analysis $\& 5$ Policy, 11, 1-31. 
Christensen, I. And A. Dib (2008): "The Financial Accelerator in an Estimated New Keynesian Model," Review of Economic Dynamics, 11, 155-178.

Christiano, L. J., M. Eichenbaum, and C. L. Evans (2005): "Nominal Rigidities and the Dynamic Effects of a Shock to Monetary Policy," Journal of Political Economy, 113, 1-45.

Christiano, L. J., R. Motto, and M. Rostagno (2014): "Risk Shocks," American Economic Review, 104, 27-65.

Crosbie, P. And J. Bohn (2003): Modelling Default Risk, Moody's KMV.

De Graeve, F. (2008): "The external finance premium and the macroeconomy: US post-WWII evidence," Journal of Economic Dynamics and Control, 32, 3415-3440.

Del Negro, M., R. B. Hasegawa, and F. Schorfheide (2014): "Dynamic Prediction Pools: An Investigation of Financial Frictions and Forecasting Performance," Working Paper 20575, National Bureau of Economic Research.

Diamond, D. W. And R. G. Rajan (2000): "A Theory of Bank Capital," The Journal of Finance, $55,2431-2465$.

Faust, J. And A. Gupta (2012): "Posterior Predictive Analysis for Evaluating DSGE Models," NBER Working Papers 17906, National Bureau of Economic Research, Inc.

Gertler, M. And P. Karadi (2011): "A model of unconventional monetary policy," Journal of Monetary Economics, 58, 17-34.

Gertler, M. And N. Kiyotaki (2010): "Financial Intermediation and Credit Policy in Business Cycle Analysis," in Handbook of Monetary Economics, Elsevier, vol. 3, 547-599.

Geweke, J. (2005): Contemporary Bayesian Econometrics and Statistics, Malden, MA: WileyInterscience.

Gorton, G. B. And A. Metrick (2009): "Securitized Banking and the Run on Repo," Working Paper 15223, National Bureau of Economic Research.

Holmstrom, B. And J. Tirole (1997): "Financial Intermediation, Loanable Funds, and the Real Sector," The Quarterly Journal of Economics, 112, 663-691.

Iacoviello, M. (2005): "House Prices, Borrowing Constraints, and Monetary Policy in the Business Cycle," American Economic Review, 95, 739-764.

Iacoviello, M. AND S. Neri (2010): "Housing Market Spillovers: Evidence from an Estimated DSGE Model," American Economic Journal: Macroeconomics, 2, 125-64.

Kiyotaki, N. And J. Moore (1997): “Credit Cycles," Journal of Political Economy, 105, 211-48. 
Kovrijnykh, N. And I. Livshits (2013): "Screening as a Unified Theory of Delinquency, Renegotiation, and Bankruptcy," Working Paper 340.

Leeper, E. M., N. Traum, and T. B. Walker (2011): "Clearing Up the Fiscal Multiplier Morass," NBER Working Papers 17444, National Bureau of Economic Research, Inc.

Lombardo, G. And P. McAdam (2012): "Financial market frictions in a model of the Euro area," Economic Modelling, 29, 2460-2485.

Meh, C. A. And K. Moran (2010): "The role of bank capital in the propagation of shocks," Journal of Economic Dynamics and Control, 34, 555-576.

Merola, R. (2013): "The role of financial frictions in the 2007-2008 crisis: an estimated DSGE model," Working Papers.

Merton, R. C. (1974): "On the Pricing of Corporate Debt: The Risk Structure of Interest Rates," Journal of Finance, 29, 449-70.

Morris, S. And H. S. Shin (2008): "Financial Regulation in a System Context," Brookings Papers on Economic Activity, 39, 229-274.

Paries, M. D. and A. Notarpietro (2008): "Monetary policy and housing prices in an estimated DSGE model for the US and the euro area," Working Paper Series 972, European Central Bank.

Smets, F. And R. Wouters (2007): "Shocks and Frictions in US Business Cycles: A Bayesian DSGE Approach," American Economic Review, 97, 586-606.

von Heideken, V. Q. (2009): "How Important are Financial Frictions in the United States and the Euro Area?" Scandinavian Journal of Economics, 111, 567-596. 


\section{APPENDIX}

A.1 Data And Sources

Definition of data variables

Consumption $=\mathrm{LN}[(\mathrm{PCEC} / \mathrm{GDPDEF}) / \mathrm{LNSindex}] \times 100$

Non-residential investment $=\mathrm{LN}[($ FPINR/GDPDEF $) /$ LNSindex $] \times 100$

Residential investment $=\mathrm{LN}[($ FPIR $/$ GDPDEF $) /$ LNSindex $] \times 100$

Output $=\mathrm{LN}($ GDPC96/LNSindex $) \times 100$

Hours $=\mathrm{LN}[(\mathrm{PRS} 85006023 \times \mathrm{CE} 16 \mathrm{OV} / 100) / \mathrm{LNSindex}] \times 100$

Inflation $=\mathrm{LN}(\operatorname{GDPDEF} / \operatorname{GDPDEF}(-1)) \times 100$

Real wage $=\mathrm{LN}(\mathrm{PRS} 85006103 / \mathrm{GDPDEF}) \times 100$

Interest rate $=$ Federal Funds Rate $/ 4$

Firm leverage $=\mathrm{LN}[($ Firm Asset $) /($ Firm Asset-Firm Debt $)]$, demeaned

Distance to default $=\mathrm{LN}(\mathrm{Z}$-score Distance to Default $)$

Interest rate spread $=($ Federal Funds Rate $-1 \mathrm{~m}$ Euro-Dollar Deposit Rate $) / 4$

Risk spread $=($ Moody's BAA-10 Year Treasury Spread $) / 4$ - Interest rate spread

Housing price $=\mathrm{LN}[($ Housing Price Index $/$ GDPDEF $) /($ Housing Price Index $(-1) /$ GDPDEF $(-1)] \times$ 100

Real household debt $=\mathrm{LN}[($ Household debt/GDPDEF)/(Household debt(-1)/GDPDEF $(-1)] \times 100$

\section{Data and Sourses}

GDPC96: Real Gross Domestic Product - Billions of Chained 1996 Dollars, Seasonally Adjusted Annual Rate 
Source: U.S. Department of Commerce, Bureau of Economic Analysis

GDPDEF: Gross Domestic Product - Implicit Price Deflator - 1996=100, Seasonally Adjusted

Source: U.S. Department of Commerce, Bureau of Economic Analysis

PCEC: Personal Consumption Expenditures - Billions of Dollars, Seasonally Adjusted Annual Rate

Source: U.S. Department of Commerce, Bureau of Economic Analysis

FPINR: Fixed Private Non-residential Investment - Billions of Dollars, Seasonally Adjusted Annual Rate

Source: U.S. Department of Commerce, Bureau of Economic Analysis

FPIR: Fixed Private Residential Investment - Billions of Dollars, Seasonally Adjusted Annual Rate Source: U.S. Department of Commerce, Bureau of Economic Analysis

CE16OV: Civilian Employment: Sixteen Years \& Over, Thousands, Seasonally Adjusted Source: U.S. Department of Labor: Bureau of Labor Statistics

LFU800000000: Population level - 16 Years and Older - Not Seasonally Adjusted Source: U.S. Bureau of Labor Statistics

LNS10000000: Labor Force Status : Civilian Noninstitutional Population - Age: 16 Years and Over - Seasonally Adjusted - Number in Thousands

Source: U.S. Bureau of Labor Statistics

(Before 1976: LFU800000000: Population Level - 16 Years and Older)

LNSindex: LNS10000000(1992:3)=1

PRS85006023: Nonfarm Business, All Persons, Average Weekly Hours Duration: Index, $1992=$ 100, Seasonally Adjusted

Source : U.S. Department of Labor

PRS85006103: Nonfarm Business, All Persons, Hourly Compensation Duration: Index, $1992=$ 100, Seasonally Adjusted

Source : U.S. Department of Labor

Federal Funds Rate: Averages of Daily Figures - Percent

Source: Board of Governors of the Federal Reserve System 
(Before 1954: 3-Month Treasury Bill Rate, Secondary Market Averages of Business Days, Discount Basis)

$1 \mathrm{~m}$ Euro-Dollar Deposit Rate: Averages of Daily Figures - Percent

Source: Board of Governors of the Federal Reserve System

10yr Treasury Rate: Averages of Daily Figures - Percent

Source: Board of Governors of the Federal Reserve System

Moody's BAA Rate: Averages of Daily Figures - Percent

Source: Board of Governors of the Federal Reserve System

Z-score Distance to Default: Institution Health Index

Source: Board of Governors of the Federal Reserve System

Housing Price Index: Price Indexes of New Single-Family Houses Sold Including Value of Lot, $2005=100$

Source : U.S. Census Bureau

Firm Asset: Nonfinancial Asset, Nonfinancial Corporate Business Balance Sheet (L102), Flow of Funds Accounts of the US

Source : Board of Governors of the Federal Reserve System

Firm Debt: Credit Market Instruments Liability, Nonfinancial Corporate Business Balance Sheet (L102), Flow of Funds Accounts of the US

Source : Board of Governors of the Federal Reserve System

Household Debt: Credit Market Instruments Liability, Households and Nonprofit Organizations Balance Sheet (L101), Flow of Funds Accounts of the US

Source : Board of Governors of the Federal Reserve System

A.2 Distance to Default The firm's assets are financed by equity issued at time $t$ denoted by $S_{t}$, and zero-coupon debt issued at $t\left(D_{t}\right)$ with a face value of $F$ and maturity date $M$. The market value of the firm at any date $t$ is given by the sum of the market value of debt and equity. Therefore, the accounting identity $V_{t}=S_{t}+D_{t}$, where $V_{t}$ denotes firm value, holds for each period. Under these assumptions, the bondholders are entitled to a time- $M$ cash flow of $\min \left[V_{M}, F\right]$ and since equity holders are the residual claimants, the value of equity at time $M$ is given by $\max \left[V_{M}-F, 0\right]$. 
At any time $t<M$, the value of these derivative securities is

$$
\begin{gathered}
S_{t}=e^{-r(M-t)} \mathbb{E}_{t}^{Q}\left\{\max \left[V_{M}-F, 0\right]\right\} \\
D_{t}=e^{-r(M-t)} \mathbb{E}_{t}^{Q}\left\{\min \left[V_{M}, F\right]\right\}
\end{gathered}
$$

where the expectation is taken with respect to the risk-neutral probability measure and the risk-free rate $r$ is assumed to be constant over time.

If firm value follows a geometric Brownian motion

$$
d \ln V_{t}=\left(\mu_{V}-\frac{\sigma_{V}^{2}}{2}\right) d t+\sigma_{V} d W_{t}
$$

where $\mu_{V}$ and $\sigma_{V}$ are, respectively, the expected return and volatility rates, and $W_{t}$ is a Wiener process. Under this assumption, Black-Scholes derivative pricing equations imply that (22) and (23) become

$$
\begin{gathered}
S_{t}=V_{t} \Phi\left(d_{t}\right)-F e^{r(M-t)} \Phi\left(d_{t}-\sigma_{V} \sqrt{M-t}\right) \\
D_{t}=F e^{-r(M-t)}\left(\frac{V_{t}}{F e^{-r(M-t)}} \Phi\left(-d_{t}\right)+\Phi\left(d_{t}-\sigma_{V} \sqrt{M-t}\right)\right)
\end{gathered}
$$

where $d_{t}=\left(\ln \left(V_{t} / F\right)-\left(r-\sigma_{V}^{2} / 2\right)(M-t)\right) /\left(\sigma_{V} \sqrt{M-t}\right)$ and $\Phi(\cdot)$ is the standard normal distribution function. Given that the value of the firm's assets follows a geometric Brownian motion, the value of the assets at any future date $M$ is given by:

$$
\begin{gathered}
\ln \left(V_{t+M}\right)=\ln \left(V_{t}\right)+\left(\mu_{V}-\sigma_{V}^{2} / 2\right) M+\sigma_{V} \sqrt{M} \varepsilon_{t+M} \\
\varepsilon_{t+M}=\frac{W(t+M)-W(t)}{\sqrt{M}}, \quad \varepsilon_{t+M} \sim N(0,1) \\
V_{t+M} / V_{t} \sim \mathcal{L} \mathcal{N}\left(\left(\mu_{V}-\sigma_{V}^{2} / 2\right) M, \sigma_{V}^{2} M\right)
\end{gathered}
$$

where the last line is the well-know result that $V_{t+M} / V_{t}$ has a log-normal distribution.

Therefore the probability of default is

$$
\begin{aligned}
\pi_{t}^{D} & =\operatorname{Pr}\left(\ln \left(V_{t}\right)-\ln (F)+\left(\mu-\frac{\sigma_{V}^{2}}{2}\right) M+\sigma_{V} \sqrt{M} \varepsilon_{t+M} \leq 0\right) \\
& =\operatorname{Pr}\left(-\frac{\ln \left(V_{t}\right)-\ln (F)+\left(\mu_{V}-\sigma_{V}^{2} / 2\right) M}{\sigma_{V} \sqrt{M}} \geq \varepsilon_{t+M}\right) .
\end{aligned}
$$

We can then define the distance to default as

$$
D D_{t}=\frac{\ln \left(V_{t} / F\right)+\left(\mu_{V}-\sigma_{V}^{2} / 2\right) M}{\sigma_{V} \sqrt{M}}
$$

Default occurs when the ratio of firm value to debt $\left(V_{t} / F\right)$ drops below unity or the log of the 
ratio is negative. The distance to default $D D_{t}$ can be interpreted as a z-score, which gives the number of standard deviations the log of this ratio needs to deviate from its mean in order for default to occur. In other words, the probability of bankruptcy depends upon the distance between the current value of the firm's assets and the face value of its liabilities, adjusted for the expected growth in asset value relative to asset volatility.

\section{A.3 Prior and Posterior Estimates from Original SW Model}

This subsection presents the prior and posterior estimates from original Smets and Wouters (2007), re-estimated using the data from 1974:4 to 2011:4.

Table 6: Prior and posterior distribution of structural parameters

\begin{tabular}{|c|c|c|c|c|c|c|c|c|}
\hline & & \multicolumn{3}{|c|}{ Prior Distribution } & \multicolumn{4}{|c|}{ Posterior Distribution } \\
\hline & & Distr. & Mean & St.Dev. & Median & Mean & HPD inf & HPD sup \\
\hline$\varphi$ & Non-residential capital adjustment cost & Normal & 4.00 & 1.50 & 5.04 & 5.10 & 3.40 & 6.76 \\
\hline$\sigma_{c}$ & Elasticity of intertemporal substitution & Normal & 1.50 & 0.37 & 1.03 & 1.07 & 0.76 & 1.40 \\
\hline$\lambda$ & Habit formation & Beta & 0.70 & 0.10 & 0.66 & 0.65 & 0.56 & 0.74 \\
\hline$\xi_{w}$ & Wage rigidity & Beta & 0.50 & 0.10 & 0.79 & 0.78 & 0.69 & 0.87 \\
\hline$\sigma_{l}$ & Labor elasticity & Normal & 2.00 & 0.75 & 1.57 & 1.61 & 0.62 & 2.58 \\
\hline$\xi_{p}$ & Price rigidity & Beta & 0.50 & 0.10 & 0.82 & 0.82 & 0.75 & 0.88 \\
\hline$\iota_{w}$ & Wage indexation & Beta & 0.50 & 0.15 & 0.47 & 0.47 & 0.25 & 0.70 \\
\hline$\iota_{p}$ & Price indexation & Beta & 0.50 & 0.15 & 0.30 & 0.31 & 0.15 & 0.48 \\
\hline$\Psi$ & Capital Utilization & Beta & 0.50 & 0.15 & 0.70 & 0.69 & 0.53 & 0.86 \\
\hline$\Phi$ & Fixed cost in production & Normal & 1.25 & 0.12 & 1.48 & 1.48 & 1.35 & 1.60 \\
\hline$r_{\pi}$ & MP reaction to inflation & Normal & 1.50 & 0.25 & 1.86 & 1.87 & 1.58 & 2.15 \\
\hline$\rho$ & MP rigidity & Beta & 0.75 & 0.10 & 0.83 & 0.83 & 0.79 & 0.86 \\
\hline$r_{y}$ & MP reaction to output gap & Normal & 0.12 & 0.05 & 0.07 & 0.07 & 0.03 & 0.11 \\
\hline$r_{\Delta_{y}}$ & MP reaction to output gap change & Normal & 0.12 & 0.05 & 0.21 & 0.21 & 0.16 & 0.25 \\
\hline $\bar{\pi}$ & Steady-state inflation & Gamma & 0.62 & 0.10 & 0.73 & 0.73 & 0.57 & 0.88 \\
\hline $\bar{\beta}$ & Steady-state discount rate & Gamma & 0.25 & 0.10 & 0.19 & 0.19 & 0.08 & 0.30 \\
\hline $\bar{l}$ & Steady-state hours worked & Normal & 0.00 & 2.00 & 0.65 & 0.68 & -1.30 & 2.68 \\
\hline $\bar{\gamma}$ & Steady-state trend growth rate & Normal & 0.40 & 0.10 & 0.43 & 0.43 & 0.39 & 0.48 \\
\hline$\alpha$ & Capital share in production & Normal & 0.30 & 0.05 & 0.16 & 0.16 & 0.13 & 0.19 \\
\hline
\end{tabular}


Table 7: Prior and posterior distribution of shock processes

\begin{tabular}{|c|c|c|c|c|c|c|c|c|}
\hline & \multicolumn{3}{|c|}{ Prior Distribution } & \multicolumn{4}{|c|}{ Posterior Distribution } \\
\hline & & Distr. & Mean & St.Dev. & Median & Mean & HPD inf & HPD sup \\
\hline$\overline{\sigma_{a}}$ & SE, productivity & Invgam & 0.10 & 2.00 & 0.42 & 0.42 & 0.38 & 0.47 \\
\hline$\sigma_{b}$ & $\mathrm{SE}$, financial friction & Invgam & 0.10 & 2.00 & 0.11 & 0.11 & 0.07 & 0.15 \\
\hline$\sigma_{g}$ & SE, government & Invgam & 0.10 & 2.00 & 0.46 & 0.46 & 0.41 & 0.50 \\
\hline$\sigma_{I}$ & SE, investment & Invgam & 0.10 & 2.00 & 0.39 & 0.40 & 0.30 & 0.49 \\
\hline$\sigma_{r}$ & SE, monetary & Invgam & 0.10 & 2.00 & 0.23 & 0.23 & 0.20 & 0.25 \\
\hline$\sigma_{p}$ & SE, inflation markup & Invgam & 0.10 & 2.00 & 0.14 & 0.14 & 0.11 & 0.16 \\
\hline$\sigma_{w}$ & SE, wage markup & Invgam & 0.10 & 2.00 & 0.30 & 0.30 & 0.26 & 0.34 \\
\hline$\rho_{a}$ & $\mathrm{AR}(1)$, productivity & Beta & 0.50 & 0.20 & 0.96 & 0.96 & 0.92 & 0.99 \\
\hline$\rho_{b}$ & $\operatorname{AR}(1)$, financial friction & Beta & 0.50 & 0.20 & 0.82 & 0.79 & 0.64 & 0.92 \\
\hline$\rho_{g}$ & $\operatorname{AR}(1)$, government & Beta & 0.50 & 0.20 & 0.98 & 0.97 & 0.95 & 0.99 \\
\hline$\rho_{I}$ & $\operatorname{AR}(1)$, investment & Beta & 0.50 & 0.20 & 0.75 & 0.74 & 0.58 & 0.88 \\
\hline$\rho_{r}$ & $\mathrm{AR}(1)$, monetary & Beta & 0.50 & 0.20 & 0.14 & 0.14 & 0.04 & 0.24 \\
\hline$\rho_{p}$ & $\mathrm{AR}(1)$, inflation markup & Beta & 0.50 & 0.20 & 0.83 & 0.82 & 0.69 & 0.96 \\
\hline$\rho_{w}$ & $\operatorname{AR}(1)$, wage markup & Beta & 0.50 & 0.20 & 0.97 & 0.96 & 0.93 & 0.99 \\
\hline$\mu_{p}$ & MA(1), inflation markup & Beta & 0.50 & 0.20 & 0.72 & 0.71 & 0.52 & 0.89 \\
\hline$\mu_{w}$ & MA(1), wage markup & Beta & 0.50 & 0.20 & 0.93 & 0.92 & 0.87 & 0.97 \\
\hline$\rho_{g y}$ & Government spending correlation & Beta & 0.50 & 0.20 & 0.48 & 0.48 & 0.33 & 0.62 \\
\hline
\end{tabular}

\section{A.4 Log-Linearized Equilibrium Conditions of the Model}

Here we lay out log-linearized equilibrium conditions of the SW-FF model around its de-trended steady-state. We first describe the details of the financial frictions in the model and related equilibrium conditions. Equilibrium conditions for non-financial sectors, mostly close to those in the original SW model, is also presented in log-linearized forms. For further details of the original SW model, see Smets and Wouters (2007).

\section{A.4.1 Details of THE FinANCIAL FRICTIONS OF THE MODEL}

\section{De-trending}

For de-trending purposes, we define new variables such as: $\xi_{t}=\Xi_{t} / \gamma^{-\sigma_{c} t}, h_{t}=H_{t} / \gamma^{t}, k_{t}=$ $K_{t} / \gamma^{t}, k_{t}^{h}=K_{t}^{h} / \gamma^{t}, c_{t}=C_{t} / \gamma^{t}, w_{t}=W_{t} /\left(P_{t} \gamma^{t}\right), \bar{\beta}=\beta \cdot \gamma^{-\sigma_{c}}, \bar{\beta}^{\prime}=\beta^{\prime} \cdot \gamma^{-\sigma_{c}}$, where $\Xi_{t}$ is the Lagrange multiplier with regard to the budget constraint. Then the first order conditions of patient households are 


$$
\begin{aligned}
& \xi_{t}= \\
& {\left[(1-\psi)\left(c_{t}-\frac{\lambda}{\gamma} c_{t-1}\right)^{1-\sigma_{h}}+\psi \epsilon_{t}^{\psi} h_{t}^{1-\sigma_{h}}\right]^{\frac{\sigma_{h}-\sigma_{c}}{1-\sigma_{h}}}(1-\psi)\left(c_{t}-\frac{\lambda}{\gamma} c_{t-1}\right)^{-\sigma_{h}} \exp \left[\frac{\sigma_{c}-1}{1+\sigma_{l}} L_{t}^{1+\sigma_{l}}\right]} \\
& w_{t}^{h}=-\frac{U_{l, t}}{\Xi_{t} \gamma^{t}}=\left[(1-\psi)\left(c_{t}-\frac{\lambda}{\gamma} c_{t-1}\right)^{1-\sigma_{h}}+\psi \varepsilon_{t}^{\psi} h_{t}^{1-\sigma_{h}}\right] \frac{1}{1-\psi}\left(c_{t}-\frac{\lambda}{\gamma} c_{t-1}\right)^{\sigma_{h}} L_{t}^{\sigma_{l}} \\
& q_{t}^{h}=E_{t} \bar{\beta} \frac{\varepsilon_{t+1}^{\beta}}{\varepsilon_{t}^{\beta}} \cdot \frac{\xi_{t+1}}{\xi_{t}} q_{t+1}^{h}\left(1-\delta_{h}\right)+\frac{\psi \varepsilon_{t}^{\psi}}{1-\psi} \cdot \frac{\left(c_{t}-\lambda / \gamma c_{t-1}\right)^{\sigma_{h}}}{\left(h_{t}\right)^{\sigma_{h}}}
\end{aligned}
$$

The first order conditions of impatient household are

$$
\begin{aligned}
& 1=E_{t} \bar{\beta}^{\prime} \frac{\varepsilon_{t+1}^{\beta}}{\varepsilon_{t}^{\beta}} \frac{\xi_{t+1}^{\prime}}{\xi_{t}^{\prime}} \frac{R_{t}^{b}}{\Pi_{t+1}}+\Omega_{t}, \\
& q_{t}^{h}=E_{t} \bar{\beta}^{\prime} \frac{\varepsilon_{t+1}^{\beta}}{\varepsilon_{t}^{\beta}} \cdot \frac{\xi_{t+1}^{\prime}}{\xi_{t}^{\prime}} q_{t+1}^{h}\left(1-\delta_{h}\right)+\frac{\psi \epsilon_{t}^{\psi}}{1-\psi} \cdot \frac{\left(c_{t}^{\prime}-\lambda / \gamma c_{t-1}^{\prime}\right)^{\sigma_{h}}}{\left(h_{t}^{\prime}\right)^{\sigma_{h}}}+\Omega_{t} m E_{t} q_{t+1}^{h} .
\end{aligned}
$$

where we define $\Lambda_{t}$ as the Lagrange multiplier with regard to debt constraint and $\Omega_{t}$ as the ratio of Lagrange multipliers, $\Omega_{t} \equiv \Lambda_{t} / \Xi_{t}^{\prime}$.

In housing goods producer's problem, the law of motion for housing can be written as

$$
h_{t}^{a}-\left(1-\delta_{h}\right) h_{t-1}^{a} / \gamma=i h_{t}=A_{t}^{h} i k_{t}^{h}, \quad\left(h_{t}^{a}=h_{t}+h_{t}^{\prime}\right)
$$

and the optimality condition is

$$
Q_{t}^{h} A_{t}^{h}-\left\{1+s^{h}\left(\frac{i k_{t}^{h} / \gamma}{i k_{t-1}^{h}}\right)\right\}-s^{h^{\prime}}\left(\frac{i k_{t}^{h} / \gamma}{i k_{t-1}^{h}}\right) \frac{i k_{t}^{h} / \gamma}{i k_{t-1}^{h}}=0
$$

\section{Steady-state}

The following describes the steady-state of the economy with respect to the variables in the housing market. Since housing goods can be transformed from consumption goods with no cost,

the steady state price of housing goods in terms of consumption goods is 1. From (28), we obtain

$$
\begin{aligned}
& \left\{1-\bar{\beta}\left(1-\delta_{h}\right)\right\}=\frac{\psi}{1-\psi} \cdot \frac{(1-\lambda / \gamma)^{\sigma_{h}} c^{\sigma_{h}}}{h^{\sigma_{h}}}, \\
& c=\left[\frac{1-\psi}{\psi} \cdot \frac{1-\bar{\beta}\left(1-\delta_{h}\right)}{(1-\lambda / \gamma)^{\sigma_{h}}}\right]^{\frac{1}{\sigma_{h}}} h=\mu_{c h} \cdot h .
\end{aligned}
$$


From $(29)-(30)$

$$
\begin{aligned}
& \left\{1-\bar{\beta}^{\prime}\left(1-\delta_{h}\right)-\left(1-\frac{\bar{\beta}^{\prime}}{\bar{\beta}}\right) m\right\}=\frac{\psi}{1-\psi} \cdot \frac{(1-\lambda / \gamma)^{\sigma_{h}}\left(c^{\prime}\right)^{\sigma_{h}}}{\left(h^{\prime}\right)^{\sigma_{h}}}, \\
& c^{\prime}=\left[\frac{1-\psi}{\psi} \cdot \frac{1-\bar{\beta}^{\prime}\left(1-\delta_{h}\right)-\left(1-\frac{\bar{\beta}^{\prime}}{\beta}\right) m}{(1-\lambda / \gamma)^{\sigma_{h}}}\right]^{\frac{1}{\sigma_{h}}} h^{\prime}=\mu_{c h}^{\prime} \cdot h^{\prime},
\end{aligned}
$$

Define $\Upsilon \equiv 1-\frac{i}{y}-g$, we obtain

$$
\Upsilon=\frac{c}{y}+\frac{c^{\prime}}{y}+\frac{i k^{h}}{y}
$$

For the housing production side,

$$
i k^{h}=\left(1-\left(1-\delta_{h}\right) / \gamma\right) h^{a}=\mu_{i k} h^{a} .
$$

Also, from impatient households' budget constraint,

$$
\begin{gathered}
\frac{c^{\prime}}{y}+\frac{(1-\mu) g}{y}+\frac{1-\left(1-\delta_{h}\right) / \gamma}{\mu_{c h}^{\prime}} \cdot \frac{c^{\prime}}{y}-\left(1-\frac{1}{\bar{\beta} \gamma}\right) \frac{m}{\mu_{c h}^{\prime}} \frac{c^{\prime}}{y}=(1-\alpha)(1-\mu) \\
\Rightarrow \frac{c^{\prime}}{y}=\left[(1-\alpha)(1-\mu)-\frac{(1-\mu) g}{y}\right] /\left[1+\frac{1-\left(1-\delta_{h}\right) / \gamma}{\mu_{c h}^{\prime}}-\left(1-\frac{1}{\bar{\beta} \gamma}\right) \frac{m}{\mu_{c h}^{\prime}}\right], \\
\frac{c}{y}=\left[\Upsilon-\left(1+\frac{\mu_{i k}}{\mu_{c h}^{\prime}}\right) \frac{c^{\prime}}{y}\right] /\left(1+\frac{\mu_{i k}}{\mu_{c h}}\right) .
\end{gathered}
$$

\section{Log-linearization Around the Steady-state}

In the following text, log-linear variables are denoted by hat. Marginal utility of consumption is

$$
\hat{\xi}_{t}=\frac{\sigma_{h}-\sigma_{c}}{1-\sigma_{h}} \hat{j}^{t}+\left(\sigma_{c}-1\right) L^{1+\sigma_{l}} \hat{L}_{t}-\sigma_{h} \frac{\hat{c}_{t}-\lambda / \gamma \hat{c}_{t-1}}{1-\lambda / \gamma}
$$

where $\hat{j}_{t}$ is defined by

$$
\hat{j}_{t}=\frac{(1-\tau)\left(1-\sigma_{h}\right)}{1-\lambda / \gamma}\left(\hat{c}_{t}-\lambda / \gamma \hat{c}_{t-1}\right)+\tau\left(1-\sigma_{h}\right) \hat{h}^{t}+\tau \hat{\epsilon}_{t}^{\psi}, \quad \tau=\frac{\psi}{(1-\psi)(1-\lambda / \gamma)\left(\frac{c}{h}\right)^{1-\sigma_{h}+\psi}}
$$


Note $L^{1+\sigma_{l}}$ in $(41)$ can be written as

$$
L^{1+\sigma_{l}}=\frac{w^{h} L}{c}\left(1-\frac{\lambda}{\gamma}\right)^{-\sigma_{h}} /\left[\left(1-\frac{\lambda}{\gamma}\right)^{1-\sigma_{h}}+\frac{\psi}{1-\psi}\left(\frac{h}{c}\right)^{1-\sigma_{h}}\right] .
$$

Equation (28) becomes

$$
\begin{aligned}
\hat{q}_{t}^{h}= & \bar{\beta}\left(1-\delta_{h}\right) E_{t}\left[\hat{q}_{t+1}^{h}-\hat{R}_{t}+\hat{\pi}_{t+1}\right] \\
& +\frac{1-\bar{\beta}\left(1-\delta_{h}\right)}{1-\lambda / \gamma} \cdot \sigma_{h}\left[\hat{c}_{t}-\frac{\lambda}{\gamma} \hat{c}_{t-1}+\left(1-\frac{\lambda}{\gamma}\right)\left(\frac{1}{\sigma_{h}} \hat{\varepsilon}_{t}^{\psi}-\hat{h}_{t}\right)\right] .
\end{aligned}
$$

From (29),

$$
\begin{gathered}
\hat{\Omega}_{t}=\frac{-\bar{\beta}^{\prime} / \bar{\beta}}{1-\bar{\beta}^{\prime} / \bar{\beta}} E_{t}\left[\hat{\xi}_{t+1}^{\prime}-\hat{\xi}_{t}^{\prime}+\hat{R}_{t}^{b}+\hat{\varepsilon}_{t+1}^{\beta}-\hat{\varepsilon}_{t}^{\beta}-\hat{\pi}_{t+1}\right] \\
\Rightarrow E_{t}\left[\hat{\varepsilon}_{t+1}^{\beta}-\hat{\varepsilon}_{t}^{\beta}+\hat{\xi}_{t+1}^{\prime}-\hat{\xi}_{t}^{\prime}\right]=\frac{1-\bar{\beta}^{\prime} / \bar{\beta}}{-\bar{\beta}^{\prime} / \bar{\beta}} \hat{\Omega}_{t}-E_{t}\left[\hat{R}_{t}^{b}-\hat{\pi}_{t+1}\right] .
\end{gathered}
$$

From (30),

$$
\begin{aligned}
\hat{q}_{t}^{h}= & E_{t} \bar{\beta}^{\prime}\left(1-\delta_{h}\right)\left[\hat{\varepsilon}_{t+1}^{\beta}-\hat{\varepsilon}_{t}^{\beta}+\hat{\xi}_{t+1}^{\prime}-\hat{\xi}_{t}^{\prime}+\hat{q}_{t+1}^{h}\right]+m\left(1-\bar{\beta}^{\prime} / \bar{\beta}\right) E_{t}\left[\hat{\Omega}_{t}+\hat{q}_{t+1}^{h}\right] \\
& +\left[1-\bar{\beta}^{\prime}\left(1-\delta_{h}\right)-m\left(1-\bar{\beta}^{\prime} / \bar{\beta}\right)\right] \cdot \sigma_{h}\left[\frac{1}{\sigma_{h}} \hat{\epsilon}_{t}^{\psi}-\hat{h}_{t}^{\prime}+\frac{\hat{c}_{t}^{\prime}-\frac{\lambda}{\gamma} \hat{c}_{t-1}^{\prime}}{1-\frac{\lambda}{\gamma}}\right]
\end{aligned}
$$

The budget constraint of the borrowing household becomes

$$
\begin{aligned}
& \frac{c^{\prime}}{y} \hat{c}_{t}^{\prime}+(1-\mu) \hat{g}_{t}+\frac{c^{\prime} / \mu_{c h}^{\prime}}{y}\left(\hat{q}_{t}^{h}+\hat{h}_{t}\right)+\frac{m}{\gamma \bar{\beta}} \frac{c^{\prime} / \mu_{c h}^{\prime}}{y}\left(\hat{b}_{t-1}+\hat{R}_{t-1}^{b}-\hat{\pi}_{t}\right) \\
= & (1-\alpha)(1-\mu) \hat{y}_{t}+\frac{c^{\prime} / \mu_{c h}^{\prime}}{y} \frac{1-\delta_{h}}{\gamma}\left(\hat{q}_{t}^{h}+\hat{h}_{t-1}^{\prime}\right)+\frac{m c^{\prime} / \mu_{c h}^{\prime}}{y}\left(\hat{b}_{t}\right),
\end{aligned}
$$

and LTV constraint becomes

$$
\hat{b}_{t}=\hat{\varepsilon}_{t}^{d b t}+E_{t} \hat{q}_{t+1}^{h}+\hat{h}_{t}^{\prime} .
$$

Law of motion for the gross housing goods and the optimality condition for the housing goods producing firms (31) and (32) become

$$
\left[1 /\left(1-\frac{1-\delta_{h}}{\gamma}\right)\right] \hat{h}_{t}^{a}-\left[\frac{1-\delta_{h}}{\gamma} /\left(1-\frac{1-\delta_{h}}{\gamma}\right)\right] \hat{h}_{t-1}^{a}=\hat{a}_{t}^{h}+\hat{i k}_{t}^{h}
$$




$$
\hat{q}_{t}^{h}+\hat{a}_{t}^{h}-S^{\prime \prime}(\gamma)^{2}\left(\hat{k}_{t}^{h}-i \hat{k}_{t-1}^{h}\right)=0
$$

Aggregate resource constraint is given by

$$
\hat{y}_{t}=\frac{c}{y} \hat{c}_{t}+\frac{i}{y} \hat{i}_{t}+\frac{i k}{y} \hat{k}_{t}+r^{k s s} \frac{k}{y} \hat{z}_{t}+\hat{\varepsilon}_{t}^{g}
$$

Regarding the financial frictions in the business sector, the marginal productivity of capital $\hat{x}_{t}$ is given by

$$
\hat{x}_{t}=\hat{l}_{t}+\hat{w}_{t}^{a}-\hat{k}_{t}
$$

where $\hat{w}_{t}^{a}$ is the weighted average real wage of patient and impatient household. Then the return on capital is defined by

$$
\hat{r}_{t}^{k}=\left(1-\frac{1-\delta}{R^{k}}\right) \hat{x}_{t}+\frac{1-\delta}{R^{k}} \hat{q}_{t}-\hat{q}_{t-1}
$$

where $\hat{q}_{t}$ is the price of capital. Given this definition of return on capital, the log-linear form of financial accelerator equation is

$$
E_{t} \hat{r}_{t+1}^{k}-\hat{r}_{t}^{f}=\chi^{e}\left(\hat{q}_{t}+\hat{k}_{t}^{p}-n \hat{w} t\right)+\hat{\varepsilon}_{t}^{r p}
$$

where $\chi^{e}$ is the parameter that represents the elasticity of the external finance premium with regards to the entrepreneur's net worth. The law of motion for the entrepreneur's net worth is

$$
\left.\gamma n \hat{w}_{t}=\vartheta\left[\frac{K^{p}}{N W}\left(R^{k} \hat{r}_{t}^{k}-R^{f} \hat{r}_{t-1}^{f}\right)+\left(R^{K}-R^{f}\right) \frac{K^{p}}{N W}\left(\hat{q}_{t-1}+\hat{k}_{t-1}^{p}\right)+R^{f} n \hat{w}_{t-1}\right)\right]+\hat{\varepsilon}_{t}^{n w} .
$$

Regarding the financial friction for the financial intermediary sector, we have the relationship between the bank spread and the distance-to-default,

$$
\widehat{b s}_{t}=\chi^{f} \cdot \widehat{D D}_{t}+\hat{\varepsilon}_{t}^{b s}
$$

and the relationship between the bank distance-to-default and the expected housing price and capital price,

$$
\widehat{D D}_{t}=\rho^{d d} \widehat{D D}_{t-1}+\chi^{d d, H} E_{t} \hat{q}_{t+1}^{h}+\chi^{d d, Q} \hat{q}_{t}+\hat{\varepsilon}_{t}^{d d}
$$

\section{A.4.2 Other Equilibrium CONDItions}

Non-financial friction part of the SW-FF model is similar to the SW model. The production 
function of the economy is given by

$$
\hat{y}_{t}=\phi_{p}\left(\alpha \hat{k}_{t}+(1-\alpha) \hat{l}_{t}+\hat{\varepsilon}_{t}^{a}\right)
$$

and non-residential capital service is defined by

$$
\hat{k}_{t}=\hat{k}_{t-1}^{p}+\hat{u}_{t}
$$

where $\hat{k}_{t}^{p}$ is physical capital stock and $\hat{u}_{t}$ is utilization rate. The following relationship exists between the marginal cost of production and the wage and marginal productivity of capital,

$$
\widehat{m c}_{t}+\hat{\varepsilon}_{t}^{a}=\alpha \hat{x}_{t}+(1-\alpha) \hat{w}_{t}^{a} .
$$

Law of motion for the physical capital stock is given by

$$
\hat{k}_{t}^{p}=(1-\delta) / \gamma \hat{k}_{t-1}^{p}+(1-(1-\delta) / \gamma) \hat{i}_{t}+(1-(1-\delta) / \gamma) \varphi \gamma^{2} \hat{\varepsilon}_{t}^{i},
$$

where $\delta$ is the depreciation rate. From the optimality condition for the capital utilization, we have the relationship between the the marginal productivity of capital and the level of utilization,

$$
\hat{u}_{t}=\frac{1-\Psi}{\Psi} \hat{x}_{t} .
$$

Capital producer's first order condition with regards to investments gives us the following optimality condition

$$
\hat{i}_{t}=\frac{1}{1+\beta \gamma^{\left(1-\sigma_{c}\right)}} \hat{i}_{t-1}+\frac{\beta \gamma^{\left(1-\sigma_{c}\right)}}{1+\beta \gamma^{\left(1-\sigma_{c}\right)}} E_{t} \hat{i}_{t+1}+\frac{1}{\phi \gamma^{2}\left(1+\beta \gamma^{\left(1-\sigma_{c}\right)}\right)} \hat{q}_{t}+\hat{\varepsilon}_{t}^{i} .
$$

There is ? type of nominal rigidity in intermediate goods production, as only a certain fraction of intermediate good producers can choose the optimal sales price. The price of producers who cannot optimize are partially indexed to the past inflation. Optimization by price-setting producers leads to the following New Keynesian Phillips curve,

$$
\begin{aligned}
\hat{\pi}_{t}= & \frac{\beta \gamma^{\left(1-\sigma_{c}\right)}}{1+\iota_{p} \beta \gamma^{\left(1-\sigma_{c}\right)}} E_{t} \hat{\pi}_{t+1}+\frac{\iota_{p}}{1+\iota_{p} \beta \gamma^{\left(1-\sigma_{c}\right)}} \hat{\pi}_{t-1} \\
& -\frac{\left(1-\beta \gamma^{\left(1-\sigma_{c}\right)} \xi_{p}\right)\left(1-\xi_{p}\right)}{\left(1+\iota_{p} \beta \gamma^{\left(1-\sigma_{c}\right)}\right)\left(1+\left(\phi_{p}-1\right) \epsilon_{p}\right) \xi_{p}} \hat{\mu}_{t}^{p}+\hat{\varepsilon}_{t}^{p}
\end{aligned}
$$

where $\iota_{p}, \xi_{p}, \epsilon_{p}$ are the degree of indexation to past inflation, the degree of price stickiness, and the curvature of ? goods market aggregator. Also, the markup in the intermediate goods production $\hat{\mu}_{t}^{p}$ equals

$$
\hat{\mu}_{t}^{p}=\alpha\left(\hat{k}_{t}-\hat{l}_{t}\right)-\hat{w}_{t}+\hat{\varepsilon}_{t}^{a} .
$$


There is also nominal rigidity in wage decision, as only a fraction of labor unions can optimally reset nominal wage, and the other fraction only partially index their wage to the past wage. Optimality conditions lead to the expression for real wage for patient and impatient households,

$$
\begin{aligned}
\hat{w}_{t}= & \frac{\beta \gamma^{\left(1-\sigma_{c}\right)}}{1+\beta \gamma^{\left(1-\sigma_{c}\right)}}\left(E_{t} \hat{w}_{t+1}+E_{t} \hat{\pi}_{t+1}\right)+\frac{1}{1+\beta \gamma^{\left(1-\sigma_{c}\right)}}\left(\hat{w}_{t-1}+\iota_{w} \hat{\pi}_{t-1}\right) \\
& -\frac{1+\beta \gamma^{\left(1-\sigma_{c}\right)} \iota_{w}}{1+\beta \gamma^{\left(1-\sigma_{c}\right)}} \hat{\pi}_{t}-\frac{\left(1-\beta \gamma^{\left(1-\sigma_{c}\right)} \xi_{w}\right)\left(1-\xi_{w}\right)}{\left(1+\beta \gamma^{\left(1-\sigma_{c}\right)}\right)\left(1+\left(\varphi_{w}-1\right) \epsilon_{w}\right) \xi_{w}} \hat{\mu}_{t}^{w}+\hat{\varepsilon}_{t}^{w}, \\
\hat{w}_{t}^{\prime}= & \frac{\beta \gamma^{\left(1-\sigma_{c}\right)}}{1+\beta \gamma^{\left(1-\sigma_{c}\right)}}\left(E_{t} \hat{w}_{t+1}^{\prime}+E_{t} \hat{\pi}_{t+1}\right)+\frac{1}{1+\beta \gamma^{\left(1-\sigma_{c}\right)}}\left(\hat{w}_{t-1}^{\prime}+\iota_{w} \hat{\pi}_{t-1}\right) \\
& -\frac{1+\beta \gamma^{\left(1-\sigma_{c}\right)} \iota_{w}}{1+\beta \gamma^{\left(1-\sigma_{c}\right)}} \hat{\pi}_{t}-\frac{\left(1-\beta \gamma^{\left(1-\sigma_{c}\right)} \xi_{w}\right)\left(1-\xi_{w}\right)}{\left(1+\beta \gamma^{\left(1-\sigma_{c}\right)}\right)\left(1+\left(\varphi_{w}-1\right) \epsilon_{w}\right) \xi_{w}} \hat{\mu}_{t}^{w^{\prime}}+\hat{\varepsilon}_{t}^{w}
\end{aligned}
$$

where $\iota_{w}, \xi_{w}, \epsilon_{w}$ are the degree of indexation to past wage, the degree of wage stickiness,and the curvature of Kimball labor market aggregator. Also, the markups in the wage contract $\hat{\mu}_{t}^{w}, \hat{\mu}_{t}^{w^{\prime}}$ equal

$$
\hat{\mu}_{t}^{w}=\hat{w}_{t}-\sigma_{l} \hat{l}_{t}-\frac{1}{1-\lambda / \gamma}\left(\hat{c}_{t}-\lambda / \nu \hat{c}_{t-1}\right), \quad \hat{\mu}_{t}^{w^{\prime}}=\hat{w}_{t}^{\prime}-\sigma_{l} \hat{l}_{t}^{\prime}-\frac{1}{1-\lambda / \gamma}\left(\hat{c}_{t}^{\prime}-\lambda / \nu \hat{c}_{t-1}^{\prime}\right)
$$

Monetary policy sets the nominal interest rate $\hat{r}_{t}^{N}$ in a way that reacts to inflation, output gap and changes in output gap. Output gap is defined by the difference between the current output $\left(\hat{y}_{t}\right)$ and the flexible-price, flexible-wage economy output $\left(\hat{y}_{t}^{*}\right)$.

$$
\hat{r}_{t}^{N}=\rho \hat{r}_{t-1}^{N}+(1-\rho)\left[r_{\pi} \hat{\pi}_{t}+r_{y}\left(\hat{y}_{t}-\hat{y}_{t}^{*}\right)\right]+r_{\Delta y}\left[\left(\hat{y}_{t}-\hat{y}_{t}^{*}\right)-\left(\hat{y}_{t-1}-\hat{y}_{t-1}^{*}\right)\right]+\hat{\varepsilon}_{t}^{r}
$$

Regarding exogenous processes, productivity shock $\hat{\varepsilon}_{t}^{a}$, discount factor shock $\hat{\varepsilon}_{t}^{\beta}$, investment specific shock $\hat{\varepsilon}_{t}^{i}$, monetary policy shock $\hat{\varepsilon}_{t}^{r}$, lending stand shock $\hat{\varepsilon}_{t}^{d b t}$, firm net worth shock $\hat{\varepsilon}_{t}^{n w}$, risk premium shock $\hat{\varepsilon}_{t}^{r p}$, bank spread shock $\hat{\varepsilon}_{t}^{b s}$, distance-to-default shock $\hat{\varepsilon}_{t}^{d d}$, housing demand shock $\hat{\varepsilon}_{t}^{\psi}$, housing supply shock $\hat{a}_{t}^{h}$ follow $\operatorname{AR}(1)$ process. Government spending shock $\hat{\varepsilon}_{t}^{g}$ follows $\operatorname{AR}(1)$ process with a correlation with productivity shock. Inflation markup shock $\hat{\varepsilon}_{t}^{p}$ and wage markup shock $\hat{\varepsilon}_{t}^{w}$ follow $\operatorname{ARMA}(1,1)$ process. 